\title{
Orally Fast Disintegrating Cyclodextrin/Prednisolone Inclusion- Complex Nanofibrous Webs for Potential Steroid Medications
}

\author{
Asli Celebioglu,* Nancy Wang, Mehmet E. Kilic, Engin Durgun, and Tamer Uyar*
}

Cite This: Mol. Pharmaceutics 2021, 18, 4486-4500

Read Online

ABSTRACT: Prednisolone is a widely used immunosuppressive and anti-inflammatory drug type that suffers from low aqueous solubility and bioavailability. Due to the inclusion complexation with cyclodextrins (CDs), prednisolone's drawbacks that hinder its potential during the administration can be eliminated effectively. Here, we have early shown the electrospinning of free-standing nanofibrous webs of $\mathrm{CD} /$ prednisolone inclusion complexes (ICs) in the absence of a polymer matrix. In this study, hydroxypropylbeta-CD $(\mathrm{HP} \beta \mathrm{CD})$ has been used to form ICs with prednisolone and generate nanofibrous webs with a drug loading capacity of $\sim 10 \%(\mathrm{w} / \mathrm{w})$. Pullulan/prednisolone nanofibrous webs have been also fabricated as a control sample having the same drug loading $(\sim 10 \%, w / w)$. It has been demonstrated that prednisolone has
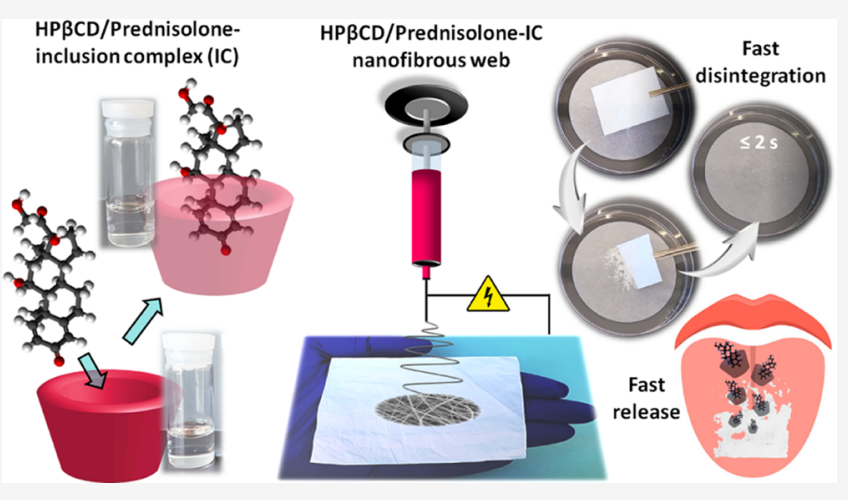
been found in an amorphous state in the $\mathrm{HP} \beta \mathrm{CD} /$ prednisolone nanofibrous web due to inclusion complexation, while it has retained its crystal structure in the pullulan/prednisolone nanofibrous web. Therefore, the $\mathrm{HP} \beta \mathrm{CD} /$ prednisolone IC nanofibrous web has shown a faster and enhanced release profile and superior disintegration feature in artificial saliva than the pullulan/ prednisolone nanofibrous web. The complexation energy calculated using ab initio modeling displayed a more favorable interaction between $\mathrm{HP} \beta \mathrm{CD}$ and prednisolone in the case of a molar ratio of 2:1 than 1:1 (CD: drug). Here, the HP $\beta \mathrm{CD} /$ prednisolone IC nanofibrous web has been developed without using a toxic component or solvent to dissolve drug molecules and boost drug loading in amorphous nature. The investigation of IC nanofibrous webs has been conducted to formulate a promising alternative to the orally disintegrating tablet formulation of prednisolone in the market. The nanofibrous structure and the improved physicochemical properties of prednisolone arising with the complexation might ensure a faster disintegration and onset of action against commercially available and orally disintegrating delivery systems during the desired treatment.

KEYWORDS: cyclodextrin, electrospinning, prednisolone, inclusion complex, fast disintegrating, oral drug delivery

\section{INTRODUCTION}

For the conformity of patients, oral drug delivery is a desirable way for the administration of drugs. ${ }^{1}$ In recent decades, orally disintegrating tablets (ODTs) have aroused growing interest in the pharmaceutical industry as an oral dosage form. ${ }^{2}$ ODTs represent acceptable safety and convenience compared to conventional tablet formulations since they can dissolve/ disintegrate in the oral cavity rapidly upon the contact with saliva, so there is no need of further liquid or chewing process during the administration. ${ }^{2}$ Besides tablet forms, orally disintegrating delivery systems (ODDSs) are being searched for the development of different treatment forms including capsules, ${ }^{3}$ wafer/patches, ${ }^{4}$ or films/strips. ${ }^{5,6}$ All these dosage formulations can offer advantages by getting an edge over conventional tablet formulations. ${ }^{7}$ The ODDSs are especially beneficial for pediatric and geriatric patients who can have trouble in chewing and swallowing during treatments or have the problem of vomiting. ${ }^{2-7}$ This system can be also suitable for bedridden patients, the ones getting local therapy, during travel, or in reduced liquid-intake care. ${ }^{2-7}$ Along with their ease of application, it is also possible to enhance the aqueous solubility, bioavailability, permeability, and delivery of poorly water-soluble drugs using ODDSs. ${ }^{5,6}$ Moreover, the side effects of formulations might be reduced by using fewer levels of active ingredients owing to the elimination of the first-pass metabolism and the rapid onset of action obtained by ODDSs. $^{8}$ On the other hand, the potential graininess which may occur by the slow disintegration of tablet formulation would lead to an unpleasant mouthfeel. ${ }^{8}$ Since it may affect the compliance of the patient, the bitter taste of the active ingredients can be another drawback of ODDSs. Additionally,

Received: August 31, 2021

Revised: November 1, 2021

Accepted: November 2, 2021

Published: November 15, 2021

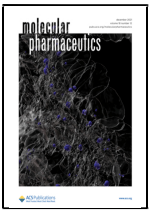




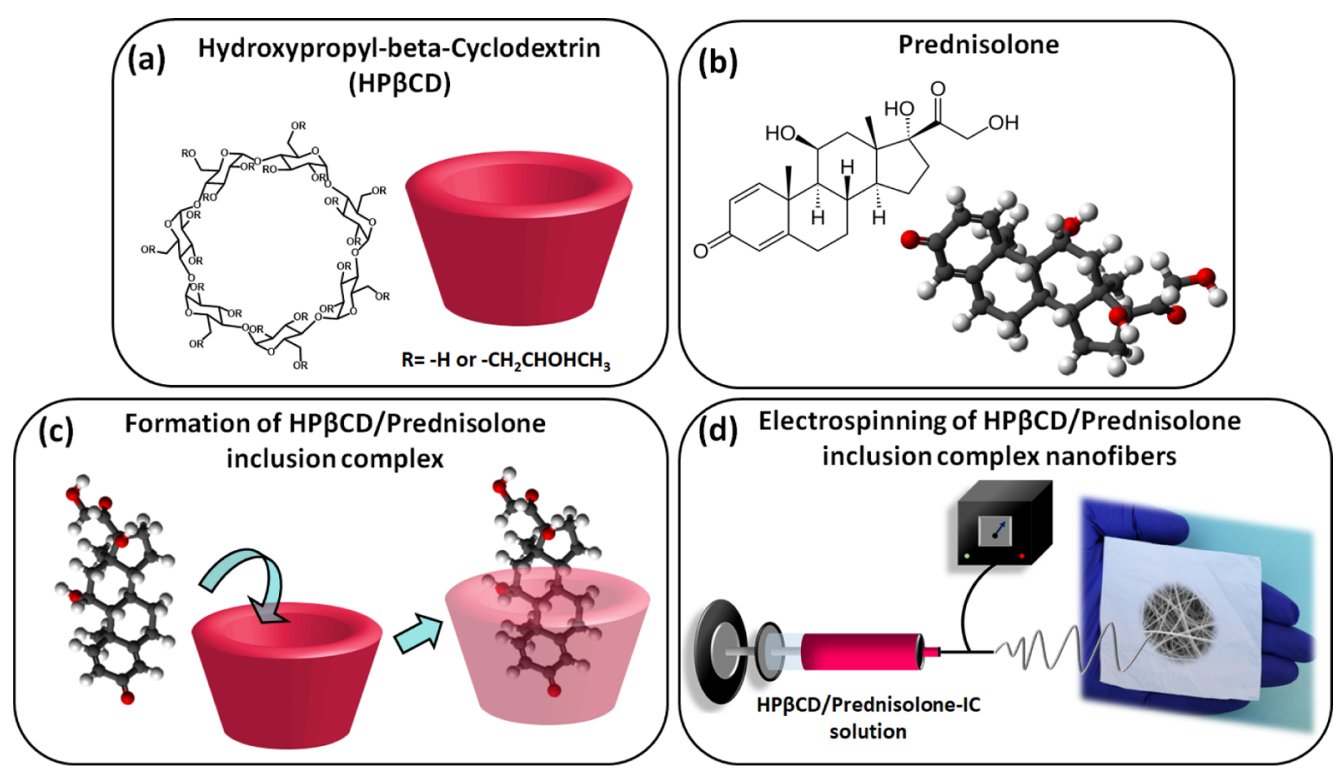

Figure 1. Main concept of the study. Chemical structure of (a) $\mathrm{H} \beta \mathrm{CD}$ and (b) prednisolone. Schematic representation of (c) IC formation between $\mathrm{H} \beta \mathrm{CD}$ and prednisolone molecules (d) and electrospinning of $\mathrm{HP} \beta \mathrm{CD} /$ prednisolone IC NFs.

depending on the technique used, fragile or brittle ODDS products may be generated as such in freeze drying. ${ }^{8}$ Taking into account all of these, finding an alternative formulation of ODDSs can be essential to be considered by maintaining the fast disintegration time ( $\leq 30 \mathrm{~s})$ requirement of the United States Food and Drug Administration.

The nanotechnological technique of electrospinning has recently drawn great attention for the development of ODDSs since it enables the generation of free-standing fibrous webs having nanoporosity and acceptable drug loading capacity. ${ }^{10-12}$ The three-dimensional (3D) porous structure, high surface area-to-volume ratio, drug carrier/release potential, and the acceptable mechanical integrity of electrospun nanofibrous webs make them an attractive alternative to form ODDSs against the known dosage form. ${ }^{11}$ Here, the high porosity and large surface area of electrospun nanofibers (NFs) contribute to easy penetration of the liquid medium and this procures the fast disintegration/dissolution profile of nanofibrous webs. ${ }^{10,11}$ Additionally, the amorphization of drug crystals provided during the electrospinning procedure by the rapid evaporation of solvent meets another important requirement of ODDSs with enhanced water solubility. ${ }^{13}$ In brief, electrospun nanofibrous webs can demonstrate faster onset of action and more rapid adsorption of drug molecules compared to conventional ODDSs. Additionally, they can eliminate the unacceptable grainy mouthfeel arising upon the administration of other formulations. As an innovative approach, the drugs in the class II-IV of the biopharmaceutical classification system (BCS) have been incorporated into electrospun nanofibrous webs of hydrophilic polymers for developing ODDSs. For this purpose, the nanofibrous webs of polyvinylpyrrolidone (PVP),${ }^{14-16}$ polyvinyl alcohol (PVA), ${ }^{17}$ Eudragit, ${ }^{18}$ gelatin, ${ }^{19}$ the polymer blends of $\mathrm{PVP} / \mathrm{PVA},{ }^{20}$ jelly fig polysaccharide/ pullulan $^{21}$ and chitosan/pullulan ${ }^{22}$ have been incorporated with different types of drug molecules including ornidazole, ${ }^{14}$ amlodipine besylate/valsartan, ${ }^{15}$ paracetamol/caffeine, ${ }^{16}$ phloretin, ${ }^{17}$ moxifloxacin hydrochloride, ${ }^{18}$ repaglinide, ${ }^{20}$ ampicil$\operatorname{lin}^{21}$ aspirin, ${ }^{22}$ and so forth. In these respective reports, nonaqueous solvents, high stirring temperature $\left(70{ }^{\circ} \mathrm{C}\right)$, or soluble salt derivates of drug molecules have been used to ensure the dissolution of both the polymer and drugs in the electrospinning solution system. As a result of the evaporation of the solvent, the recrystallization of drugs has been prevented during the process and the drug molecules have been distributed in an amorphous state in the polymeric matrix of NFs. For the rapid release profile and the fast disintegration of the substrate, the amorphous distribution of the drug molecule is essential. On the other hand, nonaqueous/toxic solvents, high process temperature, and the salt derivates of drug molecules might be undesirable in terms of the administration and the production of these formulations. Herein, cyclodextrins ( $C D s$ ) can address the disadvantages arising from the routine of polymeric systems and might be a promising alternative.

As a class of oligosaccharides, CDs have a key role in the scientific research and global market of pharmaceuticals. ${ }^{23,24}$ The inclusion complexes (ICs) formed by the noncovalent interaction between drug molecules and the CD cavity are the main source of attention for the use of these starch derivative molecules. $^{23,24}$ This unique property can improve the aqueous solubility, stability, and the bioavailability of drug molecules used in the dosage formulations. ${ }^{23-25}$ Additionally, the bitter taste of drugs can be masked and an inclusive release profile from fast to controlled/sustained release can be attained as a result of inclusion complexation with CDs. ${ }^{25,26}$ There are current studies related to the electrospinning of polymeric nanofibrous webs which have been incorporated with the CD/ drug ICs for the development of the ODDSs. ${ }^{27,28}$ On the other hand, it has been recently shown that orally disintegrating delivery formulation can be also developed by the electrospinning of $\mathrm{CD} /$ drug ICs without using a polymeric matrix for various types of drug molecules such as a pain reliever/fever reducer $\left(\right.$ paracetamol $\left.^{29}\right)$, antiviral $\left(\right.$ acyclovir $\left.^{30}\right)$, antibiotic (sulfisoxazole $^{31}$ and metronidazole ${ }^{32}$ ), and anti-inflammatory (ibuprofen $^{33}$ and hydrocortisone ${ }^{34}$ ) drugs. Here, the nanofibrous webs of $\mathrm{CD} /$ drug ICs have been generated using the aqueous system in the absence of additional organic solvents or toxic solubilizing compounds different from the polymeric 
systems. Therefore, $\mathrm{CD} / \mathrm{drug}$ IC nanofibrous webs might be more attractive compared to polymeric ones for the development of ODDSs since the complex formation can also offer an improved solubility and bioavailability for the drug molecules without using an additional agent. ${ }^{23,25}$

As a type of glucocorticoids, prednisolone is a well-known immunosuppressive and anti-inflammatory drug which has been widely used for the treatment of allergic reactions, blood disorders, endocrine and intestinal problems, cancer, eye diseases, and so forth. ${ }^{35-37}$ Prednisolone is included in the class II category of the BCS due to its low solubility and high permeability. ${ }^{38}$ The limited bioavailability arising with the low water solubility of prednisolone also results in the side effects including gastric irritation, osteoporosis, diabetes, and hypertension. $^{36-38}$ On the other hand, there are a remarkable number of studies in the literature where the side effects of prednisolone have been eliminated by forming ICs with different types of CDs. ${ }^{35,37-44}$ In these studies, it has been demonstrated that the aqueous solubility and so the bioavailability and the therapeutic potential of prednisolone can be enhanced by inclusion complexation. ${ }^{35,37-44}$ Even, Basu et al. have reported the masked bitter taste of prednisolone obtained by the inclusion complexation with $\beta \mathrm{CD}$ in the tablet that they developed as a mouth-dissolving formulation. ${ }^{43}$ The electrospinning of prednisolone incorporated nanofibrous webs has been also studied for the purpose of a sustained ${ }^{45}$ and fast release. ${ }^{46}$ In one of these related studies, Tawfik et al. have generated orally disintegrating films based on the electrospun nanofibrous web of PVA/prednisolone sodium phosphate blends, which have also shown potential for masking the unpleasant taste of prednisolone. ${ }^{46}$ The fast disintegrating nanofibrous webs of prednisolone might be an attractive alternative to the commercial ODT formulation of Orapred ODT, which is produced by using the sodium phosphate salt of prednisolone and additional stabilizers, solubilizers, sweeteners, and so forth. For this purpose, we first generated polymer-free nanofibrous webs of hydroxypropyl-beta-CD $(\mathrm{HP} \beta \mathrm{CD}) /$ prednisolone ICs as ODDSs (Figure 1) in an aqueous medium without using an additional toxic and unfavorable compound. Pullulan/prednisolone nanofibrous webs have been also fabricated as a control sample. The structure and disintegration/release profiles of samples have been examined by further analyses.

\section{EXPERIMENTAL SECTION}

2.1. Materials. $\mathrm{HP} \beta \mathrm{CD}$ was gifted by Wacker Chemie AG (USA) for scientific research. The degree of substitution (DS) of $\mathrm{HP} \beta \mathrm{CD}$ is 0.9 (2-hydroxypropyl) per glucose unit $\left(M_{\mathrm{w}}=\right.$ $1500 \mathrm{~g} / \mathrm{mol}$ ). Prednisolone (99\%, Acros Organics), pullulan $\left(M_{\mathrm{w}}: 300000 \mathrm{~g} / \mathrm{mol}\right.$, TCI America), buffer chemicals [phosphate-buffered saline (PBS) tablet (Sigma-Aldrich)], sodium phosphate dibasic heptahydrate $\left(\mathrm{Na}_{2} \mathrm{HPO}_{4}, 98.0-\right.$ $102.0 \%$, Fisher Chemical), potassium phosphate monobasic $\left(\mathrm{KH}_{2} \mathrm{PO}_{4}, \geq 99.0 \%\right.$, Fisher Chemical), sodium chloride $(\mathrm{NaCl}$, $>99 \%$, Sigma-Aldrich), o-phosphoric acid [85\% (high-performance liquid chromatography), Fisher Chemical], deuterated dimethyl sulfoxide (DMSO- $d_{6}, 99.8 \%$, Cambridge Isotope) and DMSO (> 99.9\%, Sigma-Aldrich) were used as received. A Millipore Milli-Q ultrapure water system was used for highquality distilled water.

2.2. Electrospinning of NFs. The clear aqueous solutions of $\mathrm{HP} \beta \mathrm{CD}$ and pullulan were, respectively, prepared at the concentrations of $180 \%(\mathrm{w} / \mathrm{v})$ and $20 \%(\mathrm{w} / \mathrm{v})$. Then, prednisolone powder was added into $\mathrm{HP} \beta \mathrm{CD}$ and pullulan solutions. In the case of the $\mathrm{HP} \beta \mathrm{CD}$ solution, the molar ratio of the $\mathrm{CD} /$ drug was $2: 1$ and this corresponded to $\sim 10 \%$ drug content ( $w / w$ in the total sample amount) for both $C D$ and pullulan systems. The aqueous solutions of $\mathrm{HP} \beta \mathrm{CD} /$ prednisolone and pullulan/prednisolone were mixed at room temperature under the continuous stirring for $24 \mathrm{~h}$. The $\mathrm{HP} \beta \mathrm{CD} /$ prednisolone solution turned clear due to inclusion complexation; by contrast, the turbid feature of pullulan/ prednisolone was maintained by the end of stirring. The pristine solutions of the control samples; $\operatorname{HP} \beta C D(180 \%, w / v)$ and pullulan $(20 \%, \mathrm{w} / \mathrm{v})$, which were not incorporated with prednisolone, were prepared in water, as well. The solution properties of conductivity and viscosity were measured prior to the electrospinning using a conductivity meter (FiveEasy, Mettler Toledo, USA) and rheometer (AR 2000 rheometer, TA Instrument, USA) (CP 20-4, $\left.4^{\circ}, 0.01-1000 \mathrm{~s}^{-1}, 20{ }^{\circ} \mathrm{C}\right)$, respectively. The electrospinning equipment (Spingenix, model: SG100, Palo Alto, USA) was used for the generation of NFs. For the electrospinning, the solutions were transferred into disposable plastic syringes $(1 \mathrm{~mL})$ fixated with metallic needles $(21$ or $23 \mathrm{G})$. The electrospinning solutions were fed at a stable flow rate $(0.5 \mathrm{~mL} / \mathrm{h})$, while high voltage $(15 \mathrm{kV})$ was applied to deposit NFs on the grounded metallic collector. The ambient conditions of temperature and relative humidity were, respectively, noted to be $18{ }^{\circ} \mathrm{C}$ and $25 \%$. It is important to mention that the $\mathrm{HP} \beta \mathrm{CD} /$ prednisolone aqueous system was initially prepared at a 1:1 $\mathrm{M}$ ratio; however, it was highly heterogeneous, and this precluded the electrospinning of this aqueous system into free-standing nanofibrous webs.

2.3. Structural Characterization. Scanning electron microscopy (SEM, Tescan MIRA3, Czech Republic) was employed to examine the morphology of $\mathrm{HP} \beta \mathrm{CD} /$ prednisolone-IC, pullulan/prednisolone, $\mathrm{HP} \beta \mathrm{CD}$, and pullulan nanofibrous webs. The charging problem of the samples was eliminated by sputtering with a thin layer of $\mathrm{Au} / \mathrm{Pd}$. The average diameter $(\mathrm{AD})$ (mean values \pm standard deviations) of fibers $(n=\sim 100)$ was calculated using ImageJ software. A capillary flow porometer (1100-AEHXL, Porous Media Inc., Ithaca, NY, USA) was used to determine the average pore size of the electrospun samples. Silwick having a surface tension of 20.1 dynes/cm was used as the wetting agent. For the measurements, circular pieces $(\phi=\sim 26 \mathrm{~mm})$ from different locations of nanofibrous webs were cut (weight $=\sim 20 \mathrm{mg}$ and thickness $=0.20 \mathrm{~mm}$ ). At least three measurements were conducted for each sample to obtain the results as mean values \pm standard deviations.

The Fourier transform infrared (FTIR) spectra of the samples were obtained using an attenuated total reflectanceFTIR spectrometer (PerkinElmer, USA) (32 scan; 4000-600; $\left.4 \mathrm{~cm}^{-1}\right)$. The crystallinity of the samples was analyzed by an $\mathrm{X}$ ray diffractometer (Bruker D8 ADVANCE ECO, USA) (2 $\theta$ : $\left.5^{\circ}-30^{\circ} ; \mathrm{Cu} \mathrm{K} \alpha\right)$. The thermal profile of the samples was determined by using two different techniques with a differential scanning calorimeter (DSC, Q2000, TA Instruments, USA) $\left(0-250{ }^{\circ} \mathrm{C} ; 10{ }^{\circ} \mathrm{C} / \mathrm{min} ; \mathrm{N}_{2}\right)$ and thermogravimetric analyzer (TGA, Q500, TA Instruments, USA) (25-600 $\left.{ }^{\circ} \mathrm{C} ; 20{ }^{\circ} \mathrm{C} / \mathrm{min} ; \mathrm{N}_{2}\right)$. A nuclear magnetic resonance spectrometer (Bruker AV500 having an autosampler, USA) was used to record the proton nuclear magnetic resonance $\left({ }^{1} \mathrm{H}-\mathrm{NMR}\right)$ spectra $\left(16 \mathrm{scan} ; 25^{\circ} \mathrm{C}\right)$ of the samples. Here, the samples were dissolved in DMSO- $d_{6}$ with $30 \mathrm{mg} / \mathrm{mL}$ 
concentration and Mestranova software was applied to process the recorded spectra.

2.4. Pharmacotechnical Tests. The loading efficiencies of $\mathrm{HP} \beta \mathrm{CD} /$ prednisolone-IC and pullulan/prednisolone nanofibrous webs were calculated by dissolving a definite weight of the samples $(\sim 2 \mathrm{mg})$ in DMSO $(5 \mathrm{~mL})$ and by subsequent UV measurement (UV-vis spectroscopy, PerkinElmer, Lambda 35, USA, $260 \mathrm{~nm}$ ) of these solutions. The calibration curve of prednisolone in DMSO indicated linearity with $\mathrm{R}^{2} \geq$ 0.99 , and triplicate measurements were performed for each sample to attain the results as mean values \pm standard deviations. The loading efficiency was determined using the following equation.

$$
\text { loading efficiency }(\%)=C_{\mathrm{e}} / C_{\mathrm{t}} \times 100
$$

where $C_{\mathrm{e}}$ and $C_{\mathrm{t}}$ are, respectively, the concentration of loaded prednisolone [loading capacity, $\%(\mathrm{w} / \mathrm{w})$ ] and the initial concentration $(\%, \mathrm{w} / \mathrm{w})$ of prednisolone. Here, DMSO was selected to ensure the complete dissolution of all components of the samples including $\mathrm{HP} \beta \mathrm{CD}$, prednisolone, and pullulan.

A phase solubility test was conducted on a $\mathrm{HP} \beta \mathrm{CD} /$ prednisolone system as studied previously. ${ }^{47}$ An excess amount of prednisolone $(\sim 2.7 \mathrm{mM})$ and $\mathrm{HP} \beta \mathrm{CD}$ with increasing concentration from 0 to $6 \mathrm{mM}$ was mixed in water under continuous shaking on an incubator shaker for $24 \mathrm{~h}$ (room temperature, $450 \mathrm{rpm}$ ) by shielding from light. Each suspension was then filtered with $0.45 \mu \mathrm{m}$ PTFE filters and measured using UV-vis spectroscopy $(250 \mathrm{~nm})$. The tests were performed in triplicate $(n=3)$. For plotting the phase solubility diagram, the calibration curve $\left(R^{2} \geq 0.99\right)$ of prednisolone in water was used to adapt absorbance intensity to the concentration $(\mathrm{mM})$ values. The linear part of the diagram was also applied to calculate the binding constant $\left(K_{\mathrm{S}}\right)$ using the equation below.

$$
K_{\mathrm{s}}=\text { slope } / S_{0}(1-\text { slope })
$$

where $S_{0}$ is the intrinsic solubility of prednisolone $(\sim 0.6 \mathrm{mM})$.

The time-dependent in vitro release profile of $\mathrm{HP} \beta \mathrm{CD} /$ prednisolone-IC and pullulan/prednisolone nanofibrous webs was examined under the experimental conditions of $\sim 1 \mathrm{mg} /$ $\mathrm{mL}$ sample concentration in the PBS buffer solution ( $\mathrm{pH} 7.4$ ) at $37{ }^{\circ} \mathrm{C}$ with $200 \mathrm{rpm}$ speed of the incubator shaker. Here, $250 \mu \mathrm{L}$ of the test solution was withdrawn at each predetermined time interval and the fresh liquid medium was again added to the same solutions. The released prednisolone percentage (\%) from nanofibrous webs was calculated by using $\mathrm{UV}$-vis spectroscopy measurements of the withdrawn aliquots $(250 \mathrm{~nm})$. The tests were performed 3 times (mean values \pm standard deviations), and the release kinetics of each sample was studied using different kinetic models (see the Supporting Information).

The dissolution profile of $\mathrm{HP} \beta \mathrm{CD} /$ prednisolone-IC and pullulan/prednisolone nanofibrous webs was also examined in the PBS buffer solution ( $\mathrm{pH}$ 7.4) using the same sample concentration of $1 \mathrm{mg} / \mathrm{mL}$. Here, the pristine $\mathrm{HP} \beta \mathrm{CD}$ and pullulan nanofibrous webs were also tested for comparison. A video was recorded concurrently during the addition of the aqueous medium into glass vials (Video S1). On the other hand, the disintegration profile of the same samples was evaluated by simulating the physicochemical environment of the tongue. ${ }^{48}$ For this, filter papers having a proper size in Petri dishes were wetted using artificial saliva, which was prepared by mixing $2.38 \mathrm{~g} \mathrm{Na}_{2} \mathrm{HPO}_{4}, 0.190 \mathrm{~g} \mathrm{KH}_{2} \mathrm{PO}_{4}$, and $8 \mathrm{~g} \mathrm{NaCl}$ in
$1 \mathrm{~L}$ of distilled water and further adjusting its $\mathrm{pH}$ to 6.8 with phosphoric acid. Then, the excess amount of artificial saliva was removed from the Petri dishes and the nanofibrous webs $(\sim 4.5 \times 3.5 \mathrm{~cm})$ were separately placed on the top of the wetted filter papers. The experiment was also video-recorded (Videos S2 and S3).

2.5. Computational Methodology. We employed ab initio quantum mechanical calculations ${ }^{49}$ based on density functional theory (DFT) methods. ${ }^{50,51}$ The Perdew-BurkeErnzerhof form of the generalized gradient approximation was used to treat the exchange-correlation functional. ${ }^{52}$ The van der Waals corrections was included by using the D2 method of Grimme. $^{53}$ The projector augmented wave method ${ }^{54}$ was used to describe the element potentials, and energy cutoff was fixed to $520 \mathrm{eV}$. The integrations in the Brillouin zone were performed at the $\Gamma$-point. The structures of $\mathrm{HP} \beta \mathrm{CD}$ and prednisolone molecules were optimized by using the conjugate gradient method and the convergence criteria for energy and force (on atoms) were set to $10^{-5} \mathrm{eV}$ and $10^{-2} \mathrm{eV} / \AA$, respectively. The calculations in the solvent were modeled with the implicit solvation approach where continuum dielectric description was implemented. ${ }^{55}$

2.6. Statistical Analyses. OriginLab (Origin 2021, USA) was applied for the ANOVA analyses ( 0.05 level of probability). One-way of variance was used for the results of average fiber diameter, loading efficiency, and phase solubility, while two-way of variance was used for in vitro release test finding.

\section{RESULTS AND DISCUSSION}

3.1. Morphology of NFs. In this study, a $1: 1$ (CD/drug) molar ratio has been initially used to prepare the electrospinning solution of the $\mathrm{HP} \beta \mathrm{CD} /$ prednisolone system. However, the highly concentrated and viscous solution of $\mathrm{HP} \beta \mathrm{CD}(180 \%, \mathrm{w} / \mathrm{v})$, which is required to form NFs from $\mathrm{CD},{ }^{56}$ has repressed the efficient mixing of the $\mathrm{HP} \beta \mathrm{CD} /$ prednisolone (1:1) system. Therefore, 1:1 complexation and so the reasonable electrospinning yield could not be attained from the heterogeneous aqueous solution of $\mathrm{HP} \beta \mathrm{CD}$ /prednisolone $(1: 1)$. Afterward, the prednisolone content was correspondingly decreased and the $\mathrm{HP} \beta \mathrm{CD}$ /prednisolone aqueous system having a 2:1 $\mathrm{M}$ ratio $(\mathrm{CD} / \mathrm{drug})$ was prepared for the efficient electrospinning of $\mathrm{HP} \beta \mathrm{CD} /$ prednisolone-IC nanofibrous webs. The control sample of pullulan/prednisolone nanofibrous webs was also prepared with a prednisolone content of $10 \%(\mathrm{w} / \mathrm{w}$, with respect to the total sample), which corresponded to the molar ratio of $2: 1$ ( $\mathrm{CD} / \mathrm{drug})$ used for the electrospinning of $\mathrm{HP} \beta \mathrm{CD} /$ prednisolone-IC nanofibrous webs. Figure 2 shows the optical photos of the electrospinning solutions and the ultimate webs. As it is seen in Figure $2 c$, the $\mathrm{HP} \beta \mathrm{CD} /$ prednisolone solution shows a clear feature due to full complexation between $\mathrm{HP} \beta \mathrm{CD}$ and prednisolone. In contrast, the pullulan/prednisolone solution was turbid, which indicated the existence of drug crystals in the solution (Figure $2 \mathrm{~d}$ ). Even so, the free-standing nanofibrous webs were generated from both $\mathrm{HP} \beta \mathrm{CD}$ and pullulan-based systems with good flexibility and foldability (Figure 2 ). It was observed that both nanofibrous webs still preserved their free-standing and flexible structure even after 6 months of storage at the conditions of $55-65 \%$ relative humidity and $18-22{ }^{\circ} \mathrm{C}$ temperature. This suggested the long-term storage stability of the electrospun NFs. Besides their mechanical integrity, nanofibrous webs of $\mathrm{HP} \beta \mathrm{CD}$, pullulan and $\mathrm{HP} \beta \mathrm{CD} /$ 

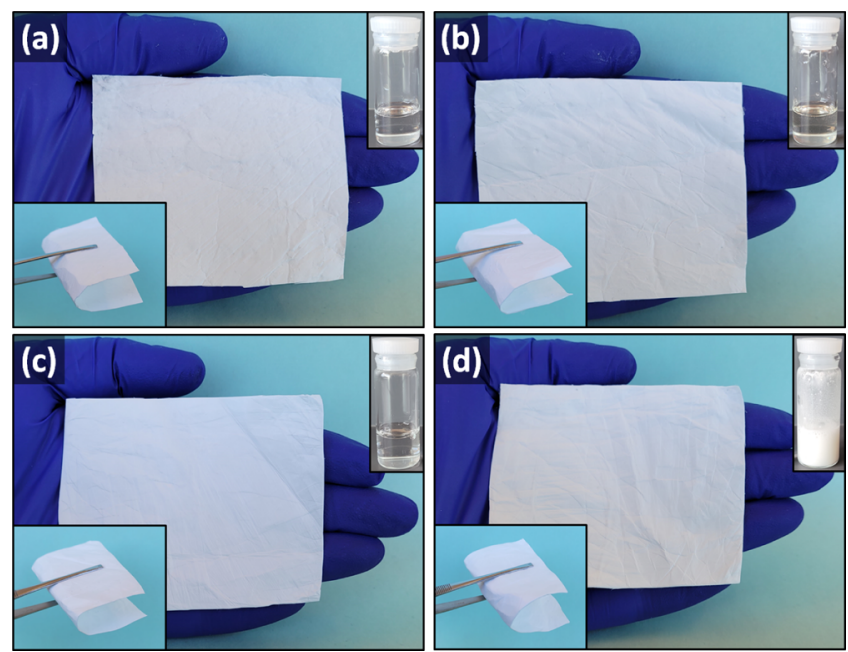

Figure 2. Visual examination of the systems. Photos of electrospinning solutions and the resulting electrospun nanofibrous webs of (a) $\mathrm{HP} \beta \mathrm{CD}$, (b) pullulan, (c) $\mathrm{HP} \beta \mathrm{CD} /$ prednisolone-IC, and (d) pullulan/prednisolone systems.

prednisolone-IC were generated along with a defect-free and homogeneous morphology (Figure 3). On the other hand, it was possible to observe the drug crystals over the fiber structure from the SEM image of pullulan/prednisolone nanofibrous webs (Figure $3 \mathrm{~d}$ ). The solution properties (viscosity and conductivity) and the $\mathrm{AD}$ of the ultimate nanofibrous webs have been listed in Table 1 . In the case of $\mathrm{HP} \beta \mathrm{CD}$-based samples, the $\mathrm{AD}$ value of $\mathrm{HP} \beta \mathrm{CD} /$ prednisolone-IC nanofibrous webs $(665 \pm 265 \mathrm{~nm})$ was higher than that of pristine $\mathrm{HP} \beta \mathrm{CD}$ nanofibrous webs $(545 \pm 220 \mathrm{~nm})$. Here, the electrospinning jet of $\mathrm{HP} \beta \mathrm{CD} /$ prednisolone was exposed to a lower stretching effect depending on its solution properties of higher viscosity and lower conductivity; hence, thicker fibers were obtained compared to the $\mathrm{HP} \beta \mathrm{CD}$ solution. $^{57}$ The polymer-based systems of pullulan also indicated a similar inclination in terms of the $\mathrm{AD}$ value and solution properties (Table 1). Pullulan and pullulan/ prednisolone nanofibrous webs were generated with quite similar $\mathrm{AD}$ values of $640 \pm 195$ and $655 \pm 100 \mathrm{~nm}$, respectively. This similarity may be attributed to equalizer viscosity and conductivity values of pullulan/prednisolone and pullulan systems, resulting in a parallel stretching effect during the electrospinning of both solutions. In this study, the average pore size of the samples has been also examined using a capillary flow porometer and the results have been summarized in Table 1. The average pore size of samples has been found in the range of $\sim 230-340 \mathrm{~nm}$. Since the AD of samples has been in a similar range, the pore size of samples has been detected in the parallel range too. In one of the related studies, Frey and $\mathrm{Li}$ have also reported that the average pore size of composite NFs of nylon/PEO having an average fiber diameter at around $150-300 \mathrm{~nm}$ has been determined as $\sim 100 \mathrm{~nm} .^{58}$

3.2. Structural Characterization. Fourier transform infrared (FTIR) spectroscopy analysis can reveal the IC formation by the shifting, broadening, or disappearance observed at the characteristic peaks of guest molecules. ${ }^{59}$ The FTIR spectra of prednisolone powder and the nanofibrous webs of $\mathrm{HP} \beta \mathrm{CD}, \mathrm{HP} \beta \mathrm{CD} /$ prednisolone-IC, pullulan, and pullulan/prednisolone have been recorded and depicted in Figure 4. The FTIR spectrum of pure prednisolone displays characteristic peaks of carbonyl groups $(\mathrm{C}=\mathrm{O})$ at 1705 and $1656 \mathrm{~cm}^{-1}$ and stretching vibration of $\mathrm{C}=\mathrm{C}$ moieties at 1614 $\mathrm{cm}^{-1} .^{35}$ On the other hand, the FTIR spectrum of $\mathrm{HP} \beta \mathrm{CD}$ indicates a broad absorption band of $-\mathrm{OH}$ in the range of $3324-3355 \mathrm{~cm}^{-1}$ and major absorption bands of coupled C$\mathrm{C} / \mathrm{C}-\mathrm{O}$ stretching and antisymmetric $\mathrm{C}-\mathrm{O}-\mathrm{C}$ glycosidic bridge stretching at 1028,1150 , and $1180 \mathrm{~cm}^{-1}$, respectively. ${ }^{60}$ Due to higher content of $\mathrm{HP} \beta \mathrm{CD}$ in the sample $(\sim 90 \%, \mathrm{w} / \mathrm{w})$, $\mathrm{CD}$ dominates these regions, and the characteristic peaks of prednisolone are hidden in the given zone (Figure 4a). Since pullulan has maltotriose repeating units which consist of glucose subunits linked by $\alpha$ - $(1,4)$ glycosidic bonds, its chemical structure is quite similar to $\mathrm{HP} \beta \mathrm{CD} .{ }^{61}$ Therefore, an analogous dominant pattern at the parallel zone of the FTIR spectra has been also observed for pullulan-based samples just like $\mathrm{HP} \beta \mathrm{CD}$ (Figure $4 \mathrm{a}){ }^{61,62}$ In the case of expanded FTIR spectra, the distinctive peaks of prednisolone are apparent in the graphs of $\mathrm{HP} \beta \mathrm{CD} /$ prednisolone-IC with shifted, broadened, or attenuated profiles, unlike the prednisolone spectrum (Figure 4b). Here, it has been found that the three main characteristic peaks of prednisolone at 1705, 1656, and $1614 \mathrm{~cm}^{-1}$ have broadened and the stretching vibration peak of $\mathrm{C}=\mathrm{O}$ at $1705 \mathrm{~cm}^{-1}$ has shifted to a higher frequency of $1713 \mathrm{~cm}^{-1}$ in the case of $\mathrm{HP} \beta \mathrm{CD} /$ prednisolone-IC NFs. Additionally, the other characteristic peaks of prednisolone at about 1406,1369 , and $1303 \mathrm{~cm}^{-1}(\delta \mathrm{O}-\mathrm{H} \text { and } \omega \mathrm{C}-\mathrm{H})^{63}$ have disappeared and all these observation can be attributed to the IC formation with $\mathrm{HP} \beta \mathrm{CD} .{ }^{35}$ On the other hand, broadening, shifting, or disappearance are not detected for the same peaks of prednisolone in the FTIR spectrum of pullulan/ prednisolone nanofibrous webs, confirming the physical mixture of the polymeric matrix and drug molecules (Figure 4b).

The IC formation has been further examined using the XRD technique. It is a convenient approach to confirm the complexation since the amorphization of the guest molecules can be followed by the disappearance of their crystalline peaks or decrease/shift in the peak intensity. ${ }^{59,64}$ Figure 5a indicates the XRD graphs of prednisolone powder and the nanofibrous webs of $\mathrm{HP} \beta \mathrm{CD}, \mathrm{HP} \beta \mathrm{CD} /$ prednisolone-IC, pullulan, and pullulan/prednisolone. The crystal structure of prednisolone is exhibited by the sharp diffraction peaks at $13.9,15.2,16.3$, and $18.0^{\circ}$. On the other hand, the amorphous nature of $\mathrm{HP} \beta \mathrm{CD}$ and pullulan is demonstrated by the broad halo patterns recorded for the given $2 \theta$ range (Figure 5a). Here, the $\mathrm{HP} \beta \mathrm{CD} /$ prednisolone-IC nanofibrous web retains a similar amorphous pattern of $\mathrm{HP} \beta \mathrm{CD}$ nanofibrous webs with the absence of prednisolone peaks, confirming the full encapsulation of drug molecules in the cavities of host molecules. ${ }^{33,65}$ Conversely, the XRD graph of pullulan/prednisolone nanofibrous webs displays the typical peaks of prednisolone, signifying the existence of undissolved drug crystals within the nanofibrous matrix. The XRD findings are coherent with the visual observation of electrospinning solutions, in which a clear solution is obtained for the $\mathrm{HP} \beta \mathrm{CD} /$ prednisolone-IC system, while a turbid dispersion forms for the pullulan/ prednisolone system (Figure 2). As has been discussed in the previous section, the drug crystals were also obvious in the SEM image of the pullulan/prednisolone nanofibrous webs (Figure 3d).

The variation in the DSC graphs of guest molecules including shifting, broadening, or the disappearance of the melting point can be attributed to the full or partial IC 

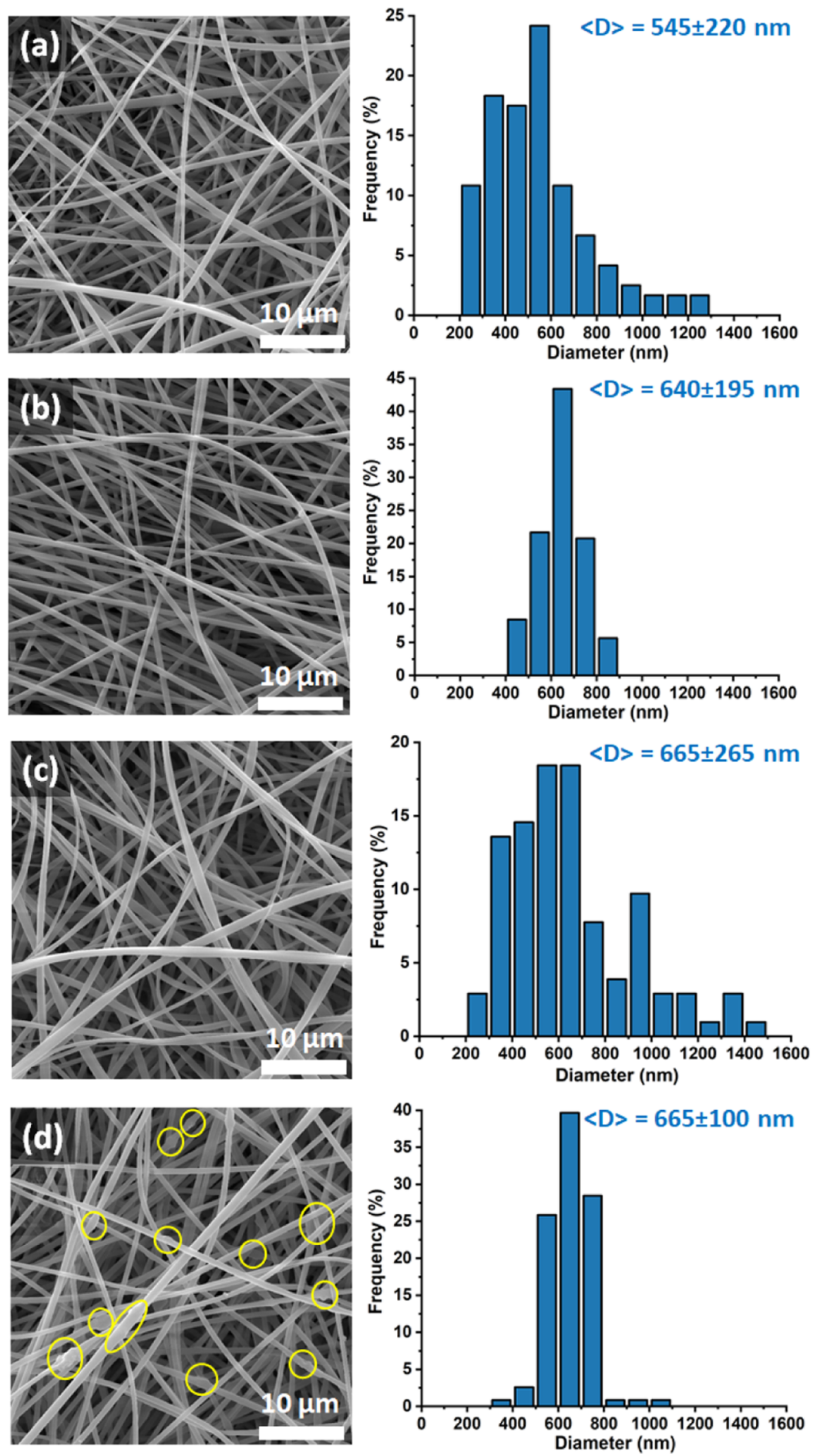

Figure 3. Morphological analyses. SEM images and the diameter distribution graphs of (a) HP $\beta$ CD, (b) pullulan, (c) HP $\beta C D /$ prednisolone-IC, (d) pullulan/prednisolone nanofibrous webs (the drug crystals have been highlighted with yellow circles) [The statistical analyses have revealed that the mean value of $\mathrm{HP} \beta \mathrm{CD}$ nanofibrous webs is significantly different from other three samples $(p<0.05)]$.

Table 1. Solution Properties of Viscosity/Conductivity and the AD/Pore Size of the Resulting Electrospun Nanofibrous Webs

\begin{tabular}{lcccccc}
\multicolumn{1}{c}{ sample } & concentration $(\%, \mathrm{w} / \mathrm{v})$ & viscosity $(\mathrm{Pa} \cdot \mathrm{s})$ & conductivity $(\mu \mathrm{S} / \mathrm{cm})$ & $\mathrm{AD}(\mathrm{nm})$ & average pore size $(\mathrm{nm})$ \\
$\mathrm{HP} \beta \mathrm{CD}$ & 180 & 0.639 & 39.6 & $545 \pm 220$ & $231 \pm 31$ \\
$\mathrm{HP} \beta \mathrm{CD} /$ prednisolone-IC & 180 & 0.879 & 37.6 & $665 \pm 265$ & $234 \pm 27$ \\
pullulan & 20 & 0.489 & 38.3 & $640 \pm 195$ & $297 \pm 39$ \\
pullulan/prednisolone & 20 & 0.722 & 44.2 & $655 \pm 100$ & $338 \pm 28$
\end{tabular}



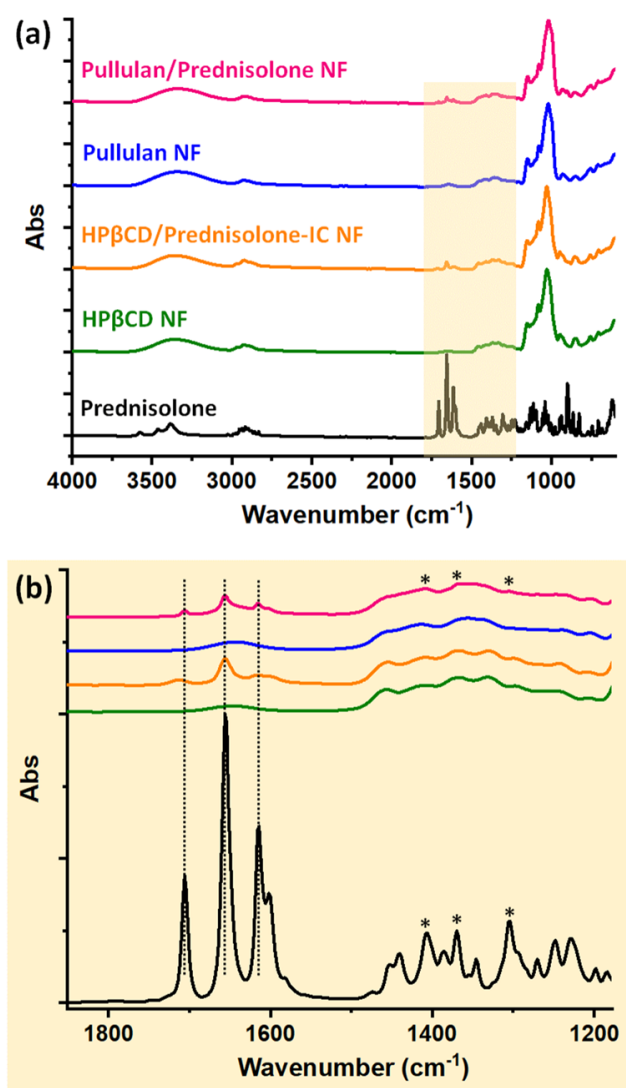

Figure 4. FTIR analyses of samples. (a) Full and (b) expanded-range FTIR spectra of prednisolone, $\mathrm{HP} \beta \mathrm{CD}$ NFs, $\mathrm{HP} \beta \mathrm{CD} /$ prednisoloneIC NFs, pullulan NFs, and pullulan/prednisolone NFs.

formation with $\mathrm{CD} .{ }^{59,64}$ Figure $5 \mathrm{~b}$ shows the DSC thermograms of prednisolone powder and the nanofibrous webs of $\mathrm{HP} \beta \mathrm{CD}, \mathrm{HP} \beta \mathrm{CD} /$ prednisolone-IC, pullulan, and pullulan/ prednisolone. Here, the prednisolone thermogram has exhibits an endothermic peak at $233^{\circ} \mathrm{C}$ assigned to its crystal structure. On the other hand, the DSC thermograms of $\mathrm{HP} \beta C D$ and pullulan NFs show the typical broad endothermic peak of dehydration. In the case of $\mathrm{HP} \beta \mathrm{CD} /$ prednisolone-IC nanofibrous webs, the melting peak of prednisolone is not detected, suggesting total inclusion complexation between prednisolone and $\mathrm{HP} \beta \mathrm{CD}$ (Figure $5 \mathrm{~b}$ ). ${ }^{33,65}$ However, for the pullulan/ prednisolone nanofibrous web, there occurs a small endother- mic peak at about $233{ }^{\circ} \mathrm{C}$ unlike the pristine pullulan sample, and this is connected with the crystal state of prednisolone in the polymeric matrix (Figure $5 \mathrm{~b}$ ). In brief, the DSC findings are correlated with the visual observations, SEM imaging, and XRD analyses, where the complete amorphization of prednisolone for $\mathrm{HP} \beta \mathrm{CD} /$ prednisolone-IC nanofibrous web and the permanency of drug crystals for pullulan/prednisolone nanofibrous web have been clearly demonstrated.

The thermal analyses of samples have been further examined using TGA. The TG and the derivate TG (DTG) curves of prednisolone and nanofibrous webs of $\mathrm{HP} \beta \mathrm{CD}, \mathrm{HP} \beta \mathrm{CD} /$ prednisolone-IC, pullulan, and pullulan/prednisolone have been depicted in Figure 6. The main degradation of $\mathrm{HP} \beta \mathrm{CD}$ and pullulan takes place in two steps of weight losses [Figure $6 \mathrm{a}, \mathrm{b}(\mathrm{i})]$. The first phase that was complete at about $100^{\circ} \mathrm{C}$ is attributed to the dehydration of water, while the main degradation of $\mathrm{HP} \beta C D$ and pullulan, respectively, occurred at $\sim 355$ and $\sim 330{ }^{\circ} \mathrm{C}$. As it is depicted in the DTG graph of prednisolone, the degradation of the drug molecule is actualized at similar ranges of $\mathrm{HP} \beta C D$ and pullulan degradation and in multiple steps that start at $180{ }^{\circ} \mathrm{C}$ and end at $495{ }^{\circ} \mathrm{C}$ [Figure $\left.6 \mathrm{a}, \mathrm{b}(\mathrm{ii})\right]$. $^{63}$ Therefore, two steps of weight losses have been observed for both $\mathrm{HP} \beta \mathrm{CD} /$ prednisolone-IC and pullulan/prednisolone nanofibrous webs. Due to the occurrence of prednisolone and IC formation with $\mathrm{CD}$, the DTG curve of $\mathrm{CD}$ reduces in intensity and becomes wider in the case of $\mathrm{HP} \beta \mathrm{CD} /$ prednisolone-IC nanofibrous webs, but none of the degradation steps of the drug molecule are separately detected [Figure $6 \mathrm{a}(\mathrm{ii})]{ }^{34}$ Since drug compounds are in an uncomplexed and crystal state in the pullulan/prednisolone nanofibrous webs, the DTG curve does not become wider compared to the curve of the pristine pullulan nanofibrous web. Additionally, the first weight loss step of prednisolone becomes apparent at about $259{ }^{\circ} \mathrm{C}$ differently from the DTG curve of the pristine pullulan nanofibrous web [Figure $6 \mathrm{~b}(\mathrm{ii})$ ]. In brief, TGA analysis demonstrates the interaction between the drug and $\mathrm{CD}$ by the modified degradation profile of $\mathrm{HP} \beta \mathrm{CD}$.

3.3. ${ }^{1} \mathrm{H}-\mathrm{NMR}$ Analysis and Loading Efficiency Test. The structure of $\mathrm{HP} \beta \mathrm{CD} /$ prednisolone-IC and pullulan/prednisolone nanofibrous webs has been analyzed using ${ }^{1} \mathrm{H}-\mathrm{NMR}$ technique as well. Figure 7 shows the ${ }^{1} \mathrm{H}-\mathrm{NMR}$ spectrum of prednisolone powder and nanofibrous webs of $\mathrm{HP} \beta \mathrm{CD} /$ prednisolone-IC and pullulan/prednisolone, while the ${ }^{1} \mathrm{H}$ NMR spectra of pristine $\mathrm{HP} \beta C D$ and pullulan nanofibrous
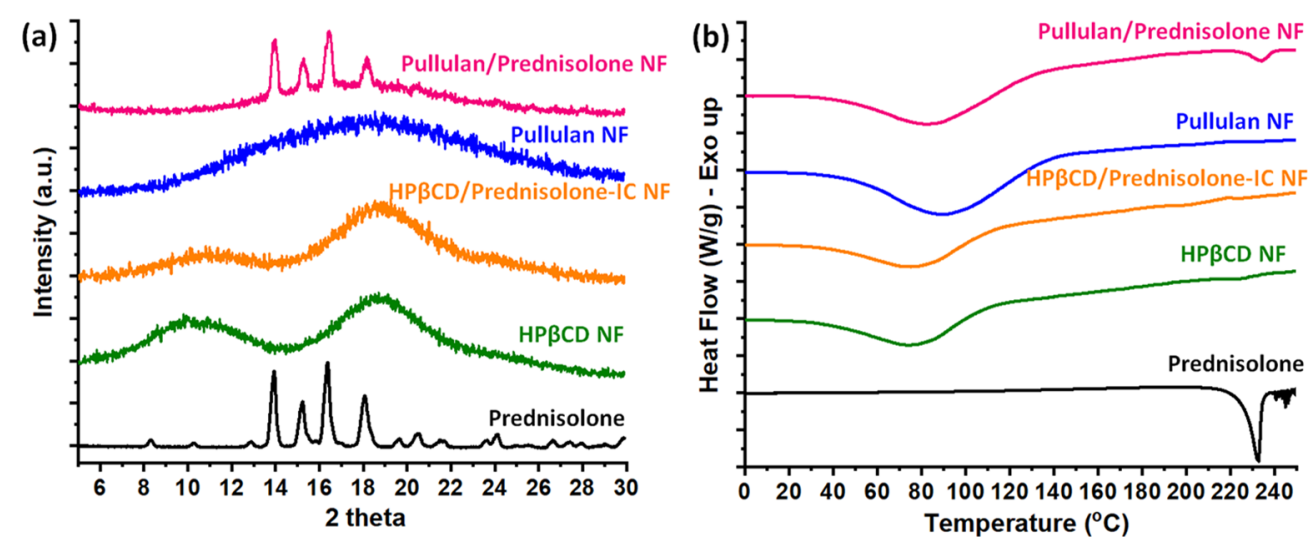

Figure 5. Examination of the crystal profile of samples. (a) XRD graphs and (b) DSC thermograms of prednisolone, HP $\beta C D$ NFs, HP $\beta C D$ / prednisolone-IC NFs, pullulan NFs, and pullulan/prednisolone NFs. 
(a-i)

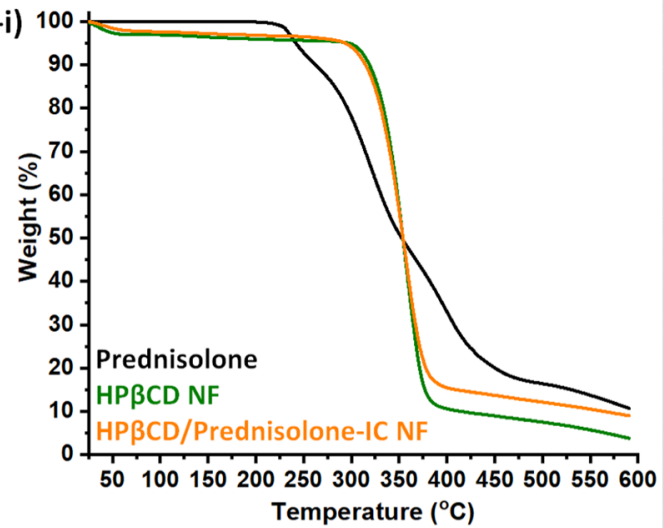

(b-i)

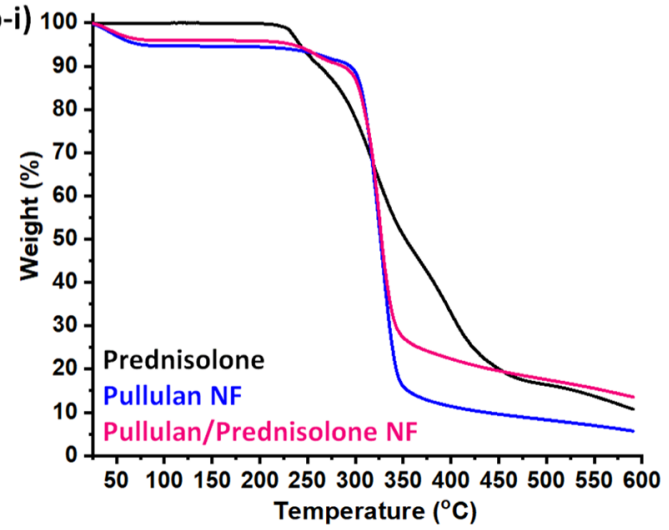

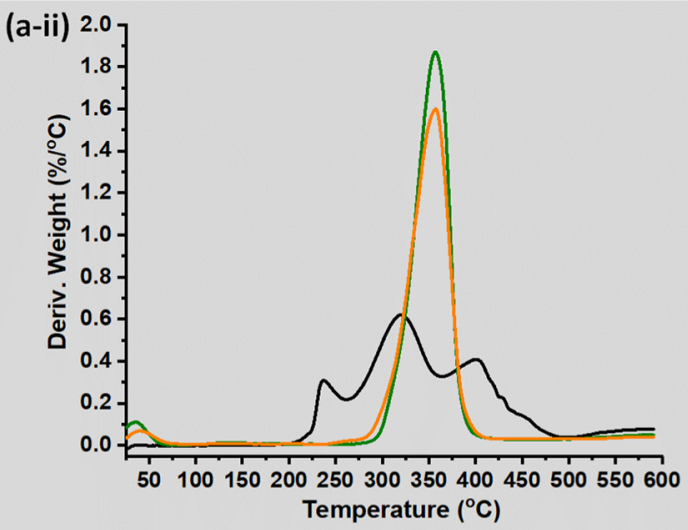

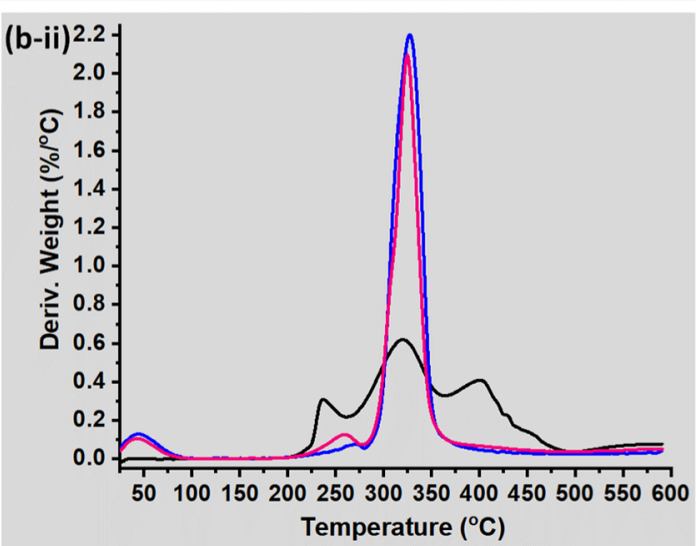

Figure 6. Thermal profile of the samples. (i) TG thermograms and (ii) DTG of (a) prednisolone, HP $\beta$ CD NFs, and HP $\beta$ CD/prednisolone-IC NFs and (b) prednisolone, pullulan NFs, and pullulan/prednisolone NFs.
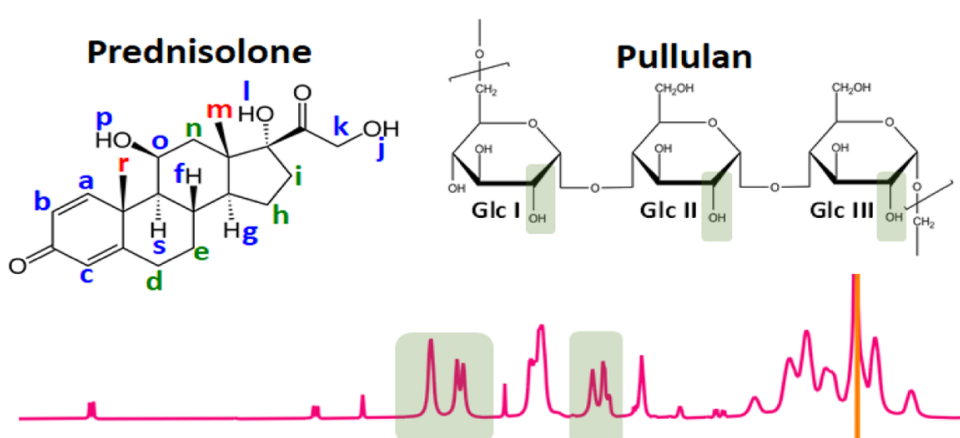

Pullulan/Prednisolone NF

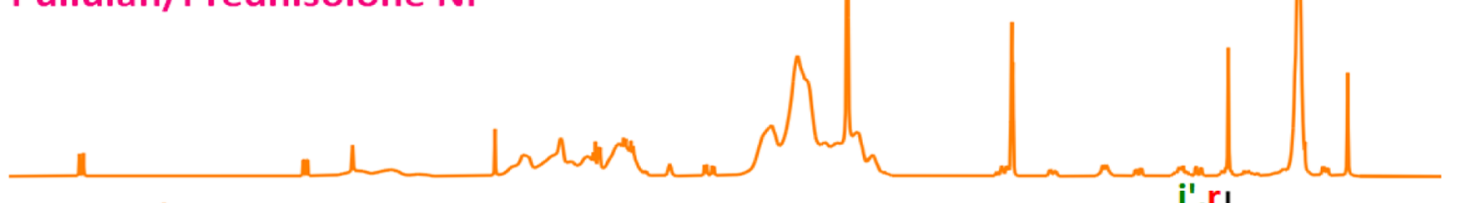

$\mathrm{HPBCD} /$ Prednisolone-IC NF

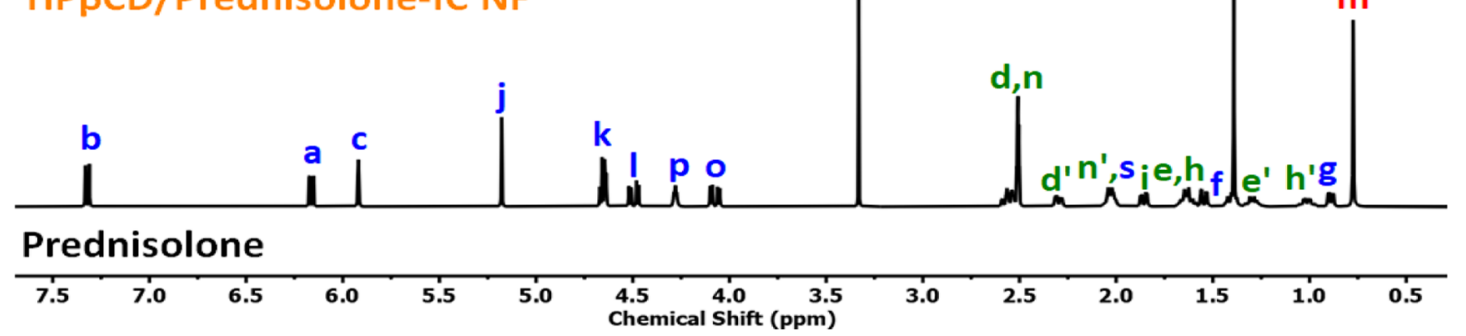

Figure 7. Chemical structure of samples. ${ }^{1} \mathrm{H}-\mathrm{NMR}$ spectra of prednisolone, $\mathrm{HP} \beta \mathrm{CD} /$ prednisolone inclusion-IC NFs, and pullulan/prednisolone NFs. The samples were dissolved in DMSO- $d_{6}$ in order to record the ${ }^{1} \mathrm{H}$-NMR spectra. 


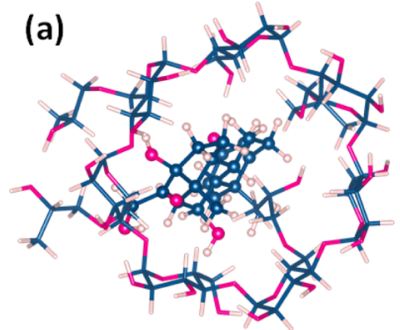

top view

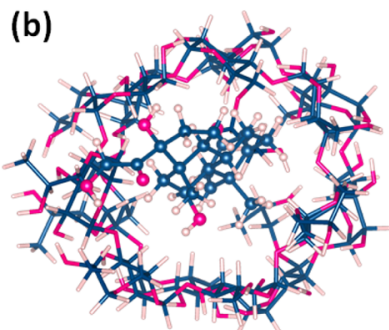

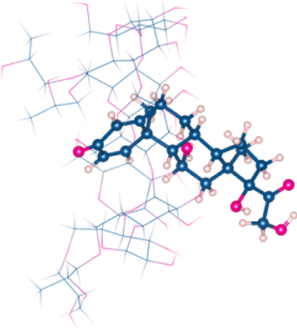

side view
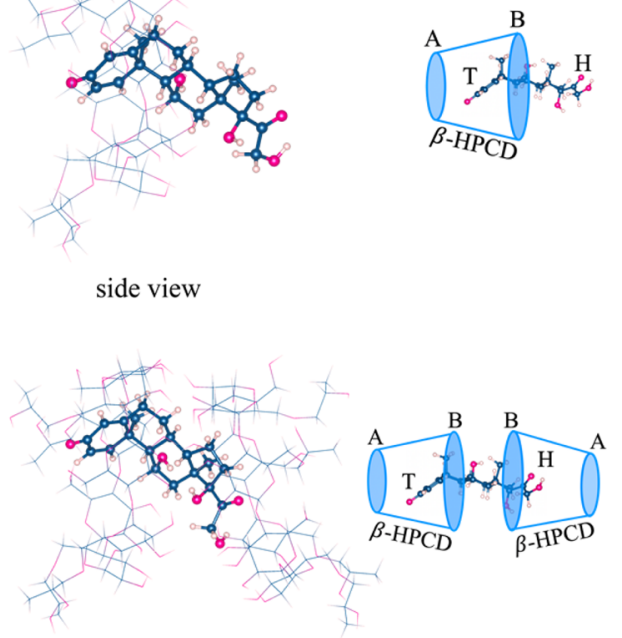

Figure 8. Modeling study showing the interaction between $\mathrm{HP} \beta \mathrm{CD}$ and prednisolone. The top and side views of $\mathrm{HP} \beta \mathrm{CD} / \mathrm{prednisolone} \mathrm{IC}$ for (a) 1:1 and (b) 2:1 stoichiometries. The orientation of prednisolone (head- $\mathrm{H}$ and tail-T) and $\mathrm{HP} \beta \mathrm{CD}$ (narrow rim-A and wide rim-B) has been labeled.

webs are shown in Figure S2. The descriptive peaks of drug molecules detected in the ${ }^{1} \mathrm{H}-\mathrm{NMR}$ spectra of nanofibrous webs verify the loading of prednisolone in the electrospun samples (Figure 7). It is obvious that the nanofibrous webs of $\mathrm{HP} \beta \mathrm{CD} /$ prednisolone-IC and pullulan/prednisolone have identical characteristic peaks of drug molecules, suggesting the protection of the chemical structure of prednisolone during the entire period of the electrospinning process. ${ }^{1} \mathrm{H}-\mathrm{NMR}$ might also be a convenient method to calculate the amount of drug molecules existing in the nanofibrous matrix. For this, prednisolone and the nanofibrous samples are dissolved in DMSO- $d_{6}$ to ensure the full dissolution of all components. The characteristic peaks of prednisolone, $\mathrm{HP} \beta \mathrm{CD}$, and pullulan located, respectively, at 5.75-7.50 ppm (H-a,b,c), ${ }^{35} 1.03 \mathrm{ppm}$ $\left(-\mathrm{CH}_{3}\right),{ }^{65}$ and $6.52-6.76 \mathrm{ppm}(-\mathrm{OH})^{66}$ have been integrated and proportioned to calculate the approximate prednisolone amount in nanofibrous webs of $\mathrm{HP} \beta \mathrm{CD} /$ prednisolone-IC and pullulan/prednisolone. It has been detected from the ${ }^{1} \mathrm{H}-\mathrm{NMR}$ results that the initial prednisolone content $(\sim 10 \%, \mathrm{w} / \mathrm{w})$, which has been used to prepare the electrospinning solution, has been effectively preserved for both electrospun nanofibrous webs. In other words, $\mathrm{HP} \beta \mathrm{CD} /$ prednisolone-IC and pullulan/prednisolone NF samples have been obtained with $\sim 100 \%$ loading efficiency.

In our study, the loading efficiency has also been further evaluated upon dissolving nanofibrous webs in DMSO. Here, the loading efficiency has been determined as $100.0 \pm 0.6$ and $98.2 \pm 5.3 \%$ for $\mathrm{HP} \beta \mathrm{CD} /$ prednisolone-IC and pullulan/ prednisolone nanofibrous webs, respectively. These results are like ${ }^{1} \mathrm{H}-\mathrm{NMR}$ findings, where the loading efficiency of the nanofibrous webs is found to be $\sim 100 \%$. As has been addressed in the previous sections, prednisolone has been found in the undissolved crystal state in pullulan/prednisolone NFs. However, DMSO- $d_{6}$ and DMSO solvent systems used in verification of loading efficiency also dissolve the crystal prednisolone in the sample and this has enabled the calculation of the drug content accurately. The statistical analyses have indicated that the variation between samples is not significant $(p>0.05)$.
3.4. Molecular Modeling Study. To reveal the complexation mechanism between $\mathrm{HP} \beta \mathrm{CD}$ and prednisolone, $\mathrm{ab}$ initio quantum mechanical calculations have been performed. Within this framework, first, the structures of $\mathrm{HP} \beta \mathrm{CD}$ and prednisolone have been optimized separately in vacuum and water. Subsequently, the interaction between $\mathrm{HP} \beta \mathrm{CD}$ and prednisolone has been investigated by taking into account different configurations. The orientation of the molecule [head (H) - tail (T)] and width of $\mathrm{CD}$ rims [narrow (A)-wide (B)] can affect the complex formation. Our analyses have indicated that the IC between $\mathrm{HP} \beta \mathrm{CD}$ and prednisolone can form spontaneously and does not require activation energy. The energetically most favorable configurations for $1: 1$ and $2: 1$ stoichiometries ( $\mathrm{HP} \beta \mathrm{CD} /$ prednisolone) have been illustrated in Figure 8. For a 1:1 M ratio, prednisolone enters $\mathrm{HP} \beta \mathrm{CD}$ through a wide rim, and tail orientation is preferred. In a similar manner, IC with a 2:1 M ratio could be obtained when the tail and head segments of prednisolone interact with the wide rims of $\mathrm{HP} \beta \mathrm{CD}$. Similar results and trends have been obtained when calculations have been performed either in vacuum or water. Once IC forms, the strength of interaction between prednisolone and $\mathrm{HP} \beta \mathrm{CD}$ can be estimated using the complexation energy $\left(E_{\mathrm{C}}\right) . E_{\mathrm{C}}$ can be calculated by using the following relation.

$$
\begin{aligned}
E_{\mathrm{C}}= & n^{*} E[\mathrm{HP} \beta \mathrm{CD}]+E[\text { prednisolone }] \\
& -E[\mathrm{HP} \beta \mathrm{CD} / \text { prednisolone }]
\end{aligned}
$$

where $E[\mathrm{HP} \beta \mathrm{CD}], E[$ prednisolone $]$, and $E[\mathrm{HP} \beta \mathrm{CD} /$ prednisolone] are the total energy of $\mathrm{HP} \beta \mathrm{CD}$, prednisolone, and $\mathrm{HP} \beta \mathrm{CD} /$ prednisolone IC, respectively. $\mathrm{n}$ is equal to 1 or 2 depending on the molar ratio. It should be noted that the energies have been calculated either in vacuum or in water. The obtained data have been listed in Table 2. $E_{\mathrm{C}}$ is high for both stoichiometries, which points out strong binding between prednisolone and $\mathrm{HP} \beta \mathrm{CD}$. Additionally, $E_{\mathrm{C}}$ significantly increased for the 2:1 ( $\mathrm{HP} \beta \mathrm{CD} /$ prednisolone) stoichiometry, indicating 2:1 as the preferred molar ratio. This observation supports the previous findings in which we could obtain freestanding nanofibrous webs from the 2:1-based $\mathrm{HP} \beta \mathrm{CD} /$ 
Table 2. Molecular Modeling Calculation Results ${ }^{a}$

$\begin{array}{ccccc}\begin{array}{c}\text { molar ratio } \\ (\mathrm{HP} \beta \mathrm{CD} / \text { prednisolone })\end{array} & \text { orientation } & \begin{array}{c}E_{\mathrm{CE}} \\ \text { kcal/mol }\end{array} & \begin{array}{c}E_{\mathrm{CE}} \\ (\text { water }) \\ \mathrm{kcal} / \mathrm{mol}\end{array} & \begin{array}{c}E_{\mathrm{SE}} \\ \mathrm{kcal} / \mathrm{mol}\end{array} \\ 1: 1 & \mathrm{H}-\mathrm{AB} & -11.54 & & \\ 1: 1 & \mathrm{~T}-\mathrm{AB} & -30.11 & -31.08 & -83.80 \\ 2: 1 & \mathrm{~T}-\mathrm{ABAB} & -29.02 & & \\ 2: 1 & \text { T-ABBA } & -85.13 & -51.72 & -115.10\end{array}$

${ }^{a}$ Complexation and solvation energies of $\mathrm{HP} \beta \mathrm{CD} /$ prednisolone IC for different orientations in 1:1 and 2:1 stoichiometries.

prednisolone-IC system in contrast to the 1:1-based one. Finally, the solvation energy $\left(E_{\mathrm{S}}\right)$, which is correlated with the solubility of the system, has been computed by the following relation.

$$
E_{\mathrm{S}}=E^{\text {water }}[\mathrm{HP} \beta \mathrm{CD} / \text { prednisolone }]-E^{\text {vacuum }}
$$

[HP $\beta \mathrm{CD} /$ prednisolone $]$

$E^{\text {water }}[\mathrm{HP} \beta \mathrm{CD} /$ prednisolone $]$ and $E^{\text {vacuum }}[\mathrm{HP} \beta \mathrm{CD} /$ prednisolone] are the total energy of $\mathrm{HP} \beta \mathrm{CD} /$ prednisolone IC in water and vacuum, respectively. The obtained values for the most favorable configurations have been given in Table 2. The significant increase in $E_{S}$ following the complex formation points out substantial enhancement in the solubility of prednisolone.

3.5. Phase Solubility Analysis and In Vitro Release Profile. The effect of increasing the $\mathrm{HP} \beta \mathrm{CD}$ concentration on the water solubility of prednisolone has been examined by phase solubility analysis. ${ }^{47}$ The phase solubility diagram which has been plotted for prednisolone concentration $(\mathrm{mM})$ against the increasing concentration of $\mathrm{HP} \beta \mathrm{CD}$ has been depicted in Figure 9a. The statistical analyses indicate that the variation between $\mathrm{HP} \beta \mathrm{CD}$ concentrations is significant $(p<0.05)$. The linear increase of the solubility of prednisolone in the given $\mathrm{HP} \beta \mathrm{CD}$ concentration range is attributed to the $\mathrm{A}_{\mathrm{L}}$-type phase solubility profile, indicating the 1:1 (molar ratio, host/guest) inclusion complexation tendency of the system. ${ }^{47}$ Our finding is correlated with the previous phase solubility studies in which the $\mathrm{A}_{\mathrm{L}}$-type diagram has been obtained for the IC system of prednisolone and $\mathrm{HP} \beta \mathrm{CD} .{ }^{42,67,68}$ On the other hand, as discussed in the molecular modeling study (Figure 8), prednisolone shows a more favorable complexation state in the case of the $2: 1 \mathrm{M}$ ratio ( $\mathrm{CD} / \mathrm{drug}$ ) compared to $1: 1$. The variance between findings might be raised from the essential differences between these two approaches. In the case of molecular modeling, the individual molecules are introduced in the water or vacuum environment to examine the interaction potential. In contrast, in the phase solubility test, the behavior of the guest molecules is followed against the increasing concentration of host molecules in the aqueous environment. Here, the water solubility of prednisolone $(\sim 0.6 \mathrm{mM})$ increases $\sim 4.8$ times for the highest $C D$ concentration of 6 $\mathrm{mM}$ (Figure 9a), and the binding constant $\left(K_{\mathrm{S}}\right)$ has been determined as $1150 \mathrm{M}^{-1}$ for the performed experimental conditions. In the respective studies, the $K_{\mathrm{S}}$ value has been reported as $556 \mathrm{M}^{-1},{ }^{67} 1286.4 \mathrm{M}^{-1}, 42$ and $1319 \mathrm{M}^{-168}$ for the $\mathrm{HP} \beta \mathrm{CD} /$ prednisolone system. It is obvious that our result has approximated the given values of the previous reports, and the variations between all these studies might originate from the experimental conditions or the different DS of hydroxypropyl groups in the used $\mathrm{HP} \beta \mathrm{CD} .^{69}$

Figure $9 \mathrm{~b}$ shows the in vitro release profile of $\mathrm{HP} \beta \mathrm{CD} /$ prednisolone and pullulan/prednisolone nanofibrous webs. Here, the HP $\beta \mathrm{CD} /$ prednisolone nanofibrous web releases 93.5 $\pm 2.9 \%$ of drug molecules in $30 \mathrm{~s}$ and an almost plateau profile is seen up to $10 \mathrm{~min}$ at which $101.0 \pm 0.9 \%$ of drug release has been attained (Figure $8 \mathrm{~b}$ ). We have obtained a similar fastrelease profile in our previous reports in which approximately all drug molecules encapsulated into IC NFs have been released into the liquid medium at the 30th second of the test. ${ }^{32,34,70}$ On the other hand, the pullulan/prednisolone nanofibrous web just released $29.6 \pm 10.6 \%$ of prednisolone in $30 \mathrm{~s}$ and reached $56.0 \pm 13.0 \%$ of drug release at the end of 10 min (Figure 9b). Our finding reveals the enhanced release profile of prednisolone in the aqueous medium, thanks to IC formation with $\mathrm{HP} \beta \mathrm{CD}$. Since prednisolone is encapsulated in the pullulan system in the crystal form, the pullulan/ prednisolone nanofibrous web shows significantly lower release $\%$ compared to $\mathrm{HP} \beta \mathrm{CD} /$ prednisolone-IC nanofibrous web. The lower solubility of the pullulan polymer $(\sim 500 \mathrm{mg} / \mathrm{mL})$ compared to $\mathrm{HP} \beta \mathrm{CD}(>2000 \mathrm{mg} / \mathrm{mL})$ might be also conducive to the worst release performance of the pullulan/ prednisolone nanofibrous web that we also observed in the dissolution test discussed in the following section. To conclude, the release of prednisolone from the pullulan/ prednisolone nanofibrous web happens by the steady dissolution of drug crystals in the liquid medium. On the other hand, the IC structure of the $\mathrm{HP} \beta \mathrm{CD} /$ prednisolone-IC nanofibrous web guarantees the rapid dissolution and the
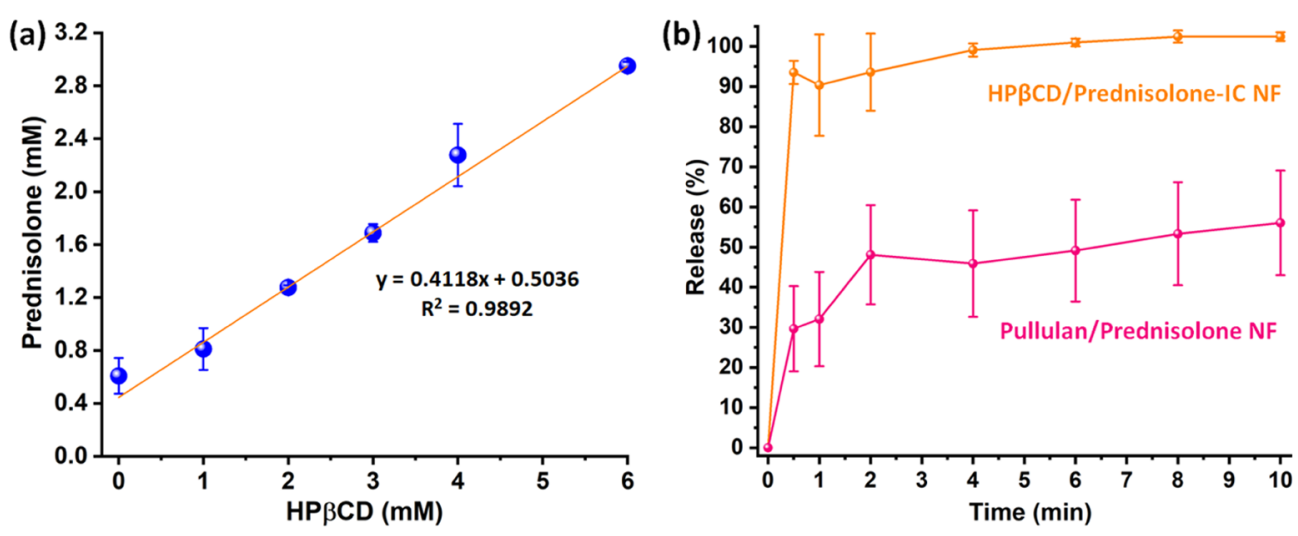

Figure 9. Physicochemical properties of the samples. (a) Phase solubility diagram of prednisolone against increasing $\mathrm{HP} \beta \mathrm{CD}$ concentration and (b) time-dependent release profile of $\mathrm{HP} \beta \mathrm{CD} /$ prednisolone-IC NFs and pullulan/prednisolone NFs. 
release profile of the sample. Additionally, the statistical analyses show significant variations between the samples $(p<$ $0.05)$.

The release profiles of the electrospun nanofibrous webs have been also examined by different kinetic models. The details of the formulations and correlation coefficient values $\left(R^{2}\right)$ (Table $S 1$ ) have been given in the Supporting Information. The results indicate that the release profile of the $\mathrm{HP} \beta \mathrm{CD} /$ prednisolone-IC nanofibrous web does not fit to the zero-/first-order and Higuchi models. These findings prove that prednisolone does not release in a time-dependent manner from a water-insoluble planar matrix in the case of the $\mathrm{HP} \beta \mathrm{CD} /$ prednisolone-IC nanofibrous web (Fick's first law). ${ }^{71}$ On the other hand, a relatively higher $R^{2}$ value (0.7785) is observed for the kinetic model of KorsmeyerPeppas compared to others, and the diffusion exponent $(n)$ value $(0.6757)$ is determined in the range of $0.45<n<0.89$. This might be attributed to the irregular/non-Fickian diffusion, diffusion-based, and erosion-controlled release of prednisolone from the $\mathrm{HP} \beta \mathrm{CD} /$ prednisolone-IC nanofibrous web. ${ }^{71,72}$ In contrast, the pullulan/prednisolone nanofibrous web displays higher $R^{2}$ values for each of the respective kinetic models than the $\mathrm{HP} \beta \mathrm{CD} /$ prednisolone-IC nanofibrous web (Table S1). As in the $\mathrm{HP} \beta \mathrm{CD} /$ prednisolone-IC nanofibrous web, the highest $R^{2}$ value $(0.8773)$ is detected for the KorsmeyerPeppas model together with an $n$ value of 0.5999 as a result of kinetic calculations of the pullulan/prednisolone nanofibrous web. This result has also demonstrated the diffusion-based and erosion-controlled release of prednisolone from the pullulan/ prednisolone nanofibrous web. ${ }^{71,72}$

3.6. Fast Dissolution and Fast Disintegration Profile. The fast dissolution property of nanofibrous webs has been tested visually by adding a PBS buffer having a $\mathrm{pH} 7.4$ (Video $\mathrm{S} 1$ and Figure 10). Since $\mathrm{HP} \beta \mathrm{CD} /$ prednisolone-IC and pullulan/prednisolone nanofibrous webs have been obtained with the same loading capacity $(10 \%, \mathrm{w} / \mathrm{w})$, the dissolution test is performed using $1 \mathrm{mg} / \mathrm{mL}$ sample concentration to ensure the identical amount of prednisolone for both electrospun webs. The pristine $\mathrm{HP} \beta \mathrm{CD}$ and pullulan nanofibrous webs $(1 \mathrm{mg} / \mathrm{mL})$ have been also evaluated for comparison. Here, the pristine $\mathrm{HP} \beta \mathrm{CD}$ nanofibrous web is instantly ( $\leq 1 \mathrm{~s})$ dissolved by the addition of the aqueous medium due to high water solubility feature of $\mathrm{HP} \beta \mathrm{CD}$. The $\mathrm{HP} \beta \mathrm{CD} /$ prednisolone-IC nanofibrous webs also rapidly disappear ( $\leq 1 \mathrm{~s})$ upon the contact of the buffer solution without an indication of undissolved prednisolone. Even pullulan is a water-soluble polymer, the pullulan nanofibrous web does not dissolve as fast as $\mathrm{HP} \beta \mathrm{CD}$-based nanofibrous webs by the addition of the liquid medium, and the pullulan web structure is still obvious at the bottom of the vial after $25 \mathrm{~s}$ (Figure 10). On the other hand, the undissolved prednisolone parts are still obvious for the pullulan/prednisolone nanofibrous web even until the end of $25 \mathrm{~s}$. Here, the crystal state of prednisolone and the lower aqueous solubility of the pullulan matrix, compared to the $\mathrm{HP} \beta \mathrm{CD}$ one, have been considered as the main reasons for the worst dissolution profile of the pullulan/prednisolone nanofibrous web. This finding has been correlated with the SEM, XRD, and DSC results, where the drug crystal in the pullulan/prednisolone nanofibrous web has been confirmed. In brief, the fast dissolution test performed visually using the identical sample concentration with the in vitro release test also suggests the enhanced water solubility of prednisolone in $\mathrm{HP} \beta \mathrm{CD}$ /prednisolone-IC nanofibrous webs.

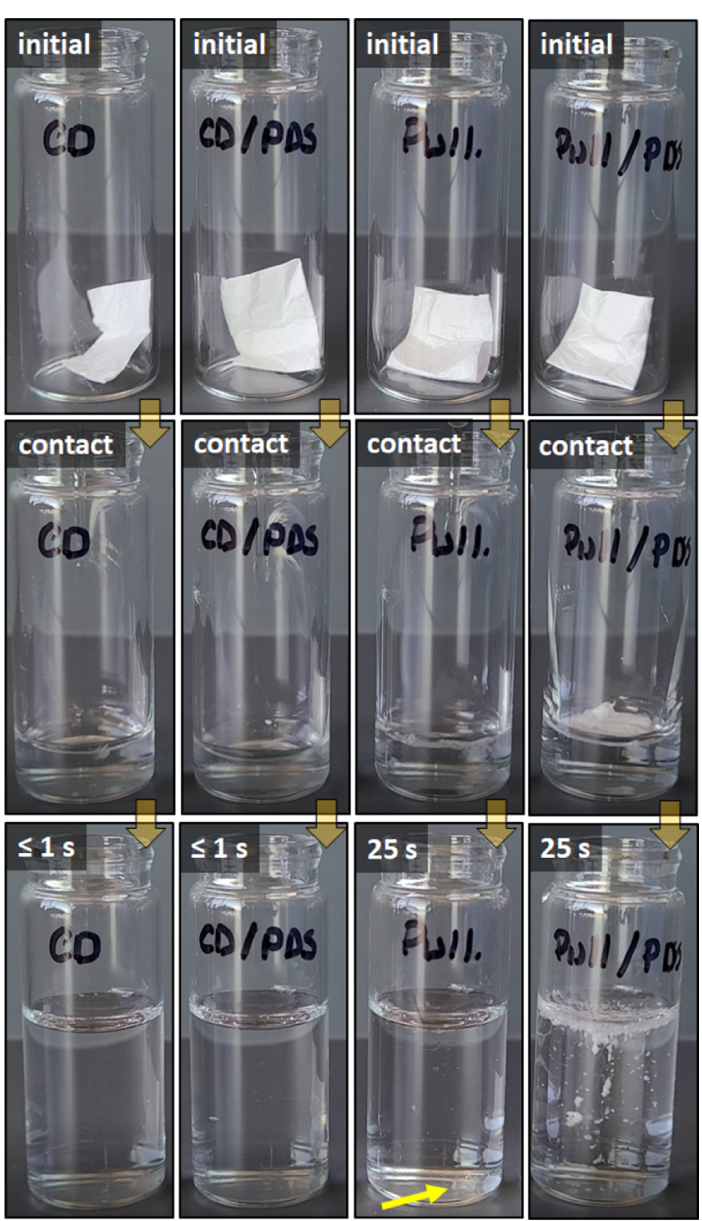

Figure 10. Dissolution profile of the samples. The dissolution behavior of the nanofibrous webs of $\mathrm{HP} \beta \mathrm{CD}(\mathrm{CD}), \mathrm{HP} \beta \mathrm{CD} /$ prednisolone-IC (CD/PDS), pullulan (Pull), and pullulan/prednisolone (Pull/PDS) in PBS buffer ( $\mathrm{pH}$ 7.4). The photos have been captured from Video S1.

The fast-disintegration profile of the electrospun nanofibrous webs has been also examined in the artificial saliva formed using a moistened filter paper to simulate the humidity in the oral cavity. ${ }^{48}$ The photos taken from the recorded Videos S2 and S3 have been categorized in Figure 11 for each sample. It is clear from both photos and videos that $\mathrm{HP} \beta \mathrm{CD}$ and $\mathrm{HP} \beta \mathrm{CD} /$ prednisolone-IC nanofibrous webs have been immediately absorbed by the moistened filter paper and disintegrated instantly in less than $2 \mathrm{~s}$ (Figure 11a,b). In contrast, the disintegration of the pullulan nanofibrous web takes more time $(\sim 20 \mathrm{~s})$ compared to $\mathrm{HP} \beta \mathrm{CD}$-based samples (Figure 11c). Even a thin layer of the pullulan/prednisolone sample is retained on the filter paper at the end of the test without disintegrating (Figure 11d). The relatively lower solubility profile of the pullulan polymer and the crystalline drug content of the sample can be the main reasons for the slower and worst disintegration profile of the pullulan/ prednisolone nanofibrous web. The more rapid disintegration feature of the $\mathrm{HP} \beta \mathrm{CD} /$ prednisolone-IC nanofibrous web might make the material more attractive and proper for the orally disintegrating formulas than the polymer-based system of pullulan by removing the potential unfavorable grainy mouth feeling. Here, the high surface area and the 3D porous structure of the nanofibrous webs are also driving influences for the fast dissolving and fast disintegrating of nanofibrous 

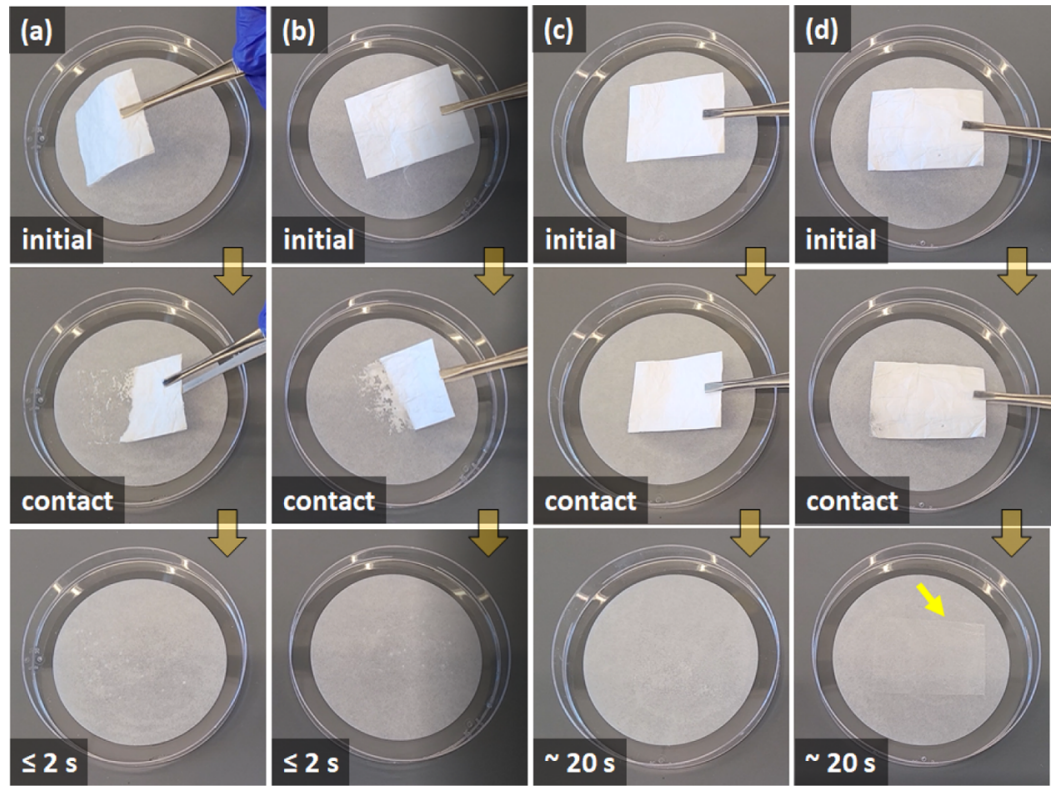

Figure 11. Disintegration profile of the samples. The disintegration behavior of the nanofibrous webs of (a) $\mathrm{HP} \beta \mathrm{CD}$, (b) $\mathrm{HP} \beta \mathrm{CD} / \mathrm{prednisolone-}$ IC, (c) pullulan, and (d) pullulan/prednisolone at the artificial saliva environment. The photos have been captured from Videos S2 and S3.

samples besides the distinct aqueous solubility of $\mathrm{HP} \beta \mathrm{CD}$. All these properties ensure the effective penetration of the liquid medium through the electrospun webs by promoting the active contact sides. Additionally, the inclusion complexation between the guest molecule and $\mathrm{HP} \beta \mathrm{CD}$, which provides the amorphous distribution of drugs in the nanofibrous webs, supports the enhanced solubility and so the fast release of prednisolone in the aqueous medium. Consequently, the $\mathrm{HP} \beta \mathrm{CD} /$ prednisolone-IC nanofibrous web might be a perfect candidate for ODDS against the polymer-based one and conventional tablet formulations.

\section{CONCLUSIONS}

This study reports the successful generation of free-standing and polymer-free nanofibrous webs of $\mathrm{HP} \beta \mathrm{CD} /$ prednisolone ICs via the electrospinning technique. Hydrophilic and polymer-based nanofibrous webs of pullulan/prednisolone have also been electrospun for comparative analysis. Due to inclusion complexation, $\mathrm{HP} \beta \mathrm{CD}$ ensures the amorphous distribution of prednisolone in the nanofibrous matrix. On the other hand, prednisolone crystals have been maintained in the case of pullulan nanofibrous webs. The faster dissolution/ disintegration of the $\mathrm{HP} \beta \mathrm{CD} /$ prednisolone-IC nanofibrous web compared to the pullulan/prednisolone one has been derived from the synergy of superior properties such as the amorphous state of prednisolone arising with inclusion complexation, high surface area and high porosity of the electrospun NFs, the high aqueous solubility of $\mathrm{HP} \beta \mathrm{CD}$. The faster disintegration of the $\mathrm{HP} \beta \mathrm{CD} /$ prednisolone-IC nanofibrous web in the artificial saliva and the more rapid and higher release of prednisolone from this web structure have been also provided by the respective advantages. There has been no need for toxic solvents or chemicals to produce the $\mathrm{HP} \beta \mathrm{CD} /$ prednisolone-IC nanofibrous web, so the use of only water might be also a huge gain during the industrialization of this novel orally disintegrating dosage formulation. To conclude, the approach of generation of polymer-free nanofibrous webs of CD ICs can be executed for the immunosuppressive and anti-inflammatory drug molecules of prednisolone. $\mathrm{HP} \beta \mathrm{CD} /$ prednisolone-IC nanofibrous webs might stand out as a promising alternative to the commercially available ODT formulations. Here, the unfavorable taste of prednisolone which can affect the compliance of the patient might be also eliminated due to inclusion complexation. Even, $\mathrm{HP} \beta \mathrm{CD} /$ prednisolone-IC nanofibrous webs might be noteworthily attractive during the treatment of allergic reactions to be free of swallowing and chewing difficulties.

\section{ASSOCIATED CONTENT}

\section{SI Supporting Information}

The Supporting Information is available free of charge at https://pubs.acs.org/doi/10.1021/acs.molpharmaceut.1c00677.

Photosof $\mathrm{HP} \beta \mathrm{CD} /$ prednisolone-IC and pullulan/prednisolone nanofibrous webs after 6 months stored at $55-65 \% \mathrm{RH}$ and $18-22{ }^{\circ} \mathrm{C}$; chemical structure and ${ }^{1} \mathrm{H}$ NMR spectra of $\mathrm{HP} \beta \mathrm{CD}$ and pullulan NFs; kinetic models calculations and their results (PDF)

Comparative dissolution profiles of nanofibrous webs of $\mathrm{HP} \beta \mathrm{CD}, \mathrm{HP} \beta \mathrm{CD} /$ prednisolone-IC, pullulan, and pullulan/prednisolone (Video S1-MP4)

Disintegration profiles of nanofibrous webs of $\mathrm{HP} \beta \mathrm{CD}$ and $\mathrm{HP} \beta \mathrm{CD} /$ prednisolone-ICs (Video S2-MP4)

Disintegration profiles of nanofibrous webs of pullulan, and pullulan/prednisolone (Video S3-MP4)

\section{AUTHOR INFORMATION}

\section{Corresponding Authors}

Asli Celebioglu - Fiber Science and Apparel Design, Cornell University, Ithaca, New York 14853, United States; ○ orcid.org/0000-0002-5563-5746; Email: ac2873@ cornell.edu

Tamer Uyar - Fiber Science and Apparel Design, Cornell University, Ithaca, New York 14853, United States; (1) orcid.org/0000-0002-3989-4481; Email: tu46@ cornell.edu 


\section{Authors}

Nancy Wang - Fiber Science and Apparel Design, Cornell University, Ithaca, New York 14853, United States

Mehmet E. Kilic - Computational Science Research Center, Korea Institute of Science and Technology, Seoul 02792,

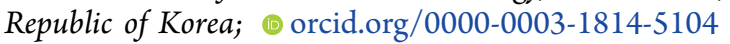

Engin Durgun - UNAM- National Nanotechnology Research Center and Institute of Materials Science and

Nanotechnology, Bilkent University, Ankara 06800, Turkey; () orcid.org/0000-0002-0639-5862

Complete contact information is available at:

https://pubs.acs.org/10.1021/acs.molpharmaceut.1c00677

\section{Author Contributions}

The manuscript was written through contributions of all authors. All authors have given approval to the final version of the manuscript.

\section{Notes}

The authors declare no competing financial interest.

\section{ACKNOWLEDGMENTS}

This work made use of the Cornell Center for Materials Research Shared Facilities which are supported through the NSF MRSEC program (DMR-1719875), the Cornell Chemistry NMR Facility supported in part by the NSF MRI program (CHE-1531632), and the Department of Fiber Science and Apparel Design facilities. T.U. acknowledges the startup funding from the College of Human Ecology at Cornell University. Partial funding for this research was also graciously provided by the Nixon Family (Lea and John Nixon) through the College of Human Ecology at Cornell University. M.E.K. acknowledges support from the Brain Pool Program through the National Research Foundation of Korea (NRF) funded by the Ministry of Science and ICT (2020H1D3A1A02081517).

\section{REFERENCES}

(1) Choi, D.-H.; Jeong, S.-H. Multi-Layered Matrix Tablets with Various Tablet Designs and Release Profiles. J. Pharm. Invest. 2011, 41, 263-272.

(2) Rahane, R.; Rachh, P. R. A Review on Fast Dissolving Tablet. J. Drug Deliv. Therapeut. 2018, 8, 50-55.

(3) Ciper, M.; Bodmeier, R. Preparation and Characterization of Novel Fast Disintegrating Capsules (Fastcaps) for Administration in the Oral Cavity. Int. J. Pharm. 2005, 303, 62-71.

(4) Patil, P. C.; Shrivastava, S. K.; Vaidehi, S.; Ashwini, P. Oral Fast Dissolving Drug Delivery System: A Modern Approach for Patient Compliance. Int. J. Drug Regul. Aff. 2014, 2, 49-60.

(5) Bala, R.; Khanna, S.; Pawar, P.; Arora, S. Orally Dissolving Strips: A New Approach to Oral Drug Delivery System. Int. J. Pharm. Invest. 2013, 3, 67-76.

(6) Kathpalia, H.; Gupte, A. An Introduction to Fast Dissolving Oral Thin Film Drug Delivery Systems: A Review. Curr. Drug Deliv. 2013, 10, 667-684.

(7) Patel, V. F.; Liu, F.; Brown, M. B. Advances in Oral Transmucosal Drug Delivery. J. Controlled Release 2011, 153, 106116.

(8) Al-Khattawi, A.; Mohammed, A. R. Challenges and Emerging Solutions in the Development of Compressed Orally Disintegrating Tablets. Expet Opin. Drug Discov. 2014, 9, 1109-1120.

(9) U.S. Department of Health and Human Services Food and Drug Administration Center for Drug Evaluation and Research (CDER). Guidance for Industry Orally Disintegrating Tablets-CDER Data Standards Manual. https://www.fda.gov/media/70877/download (accessed 2008).
(10) Balusamy, B.; Celebioglu, A.; Senthamizhan, A.; Uyar, T. Progress in the Design and Development of "Fast-Dissolving" Electrospun Nanofibers Based Drug Delivery Systems - A Systematic Review. J. Controlled Release 2020, 326, 482-509.

(11) Yu, D.-G.; Li, J.-J.; Williams, G. R.; Zhao, M. Electrospun Amorphous Solid Dispersions of Poorly Water-Soluble Drugs: A Review. J. Controlled Release 2018, 292, 91-110.

(12) Uyar, T.; Kny, E. Electrospun Materials for Tissue Engineering and Biomedical Applications: Research, Design and Commercialization; Woodhead Publishing, 2017.

(13) Seif, S.; Franzen, L.; Windbergs, M. Overcoming Drug Crystallization in Electrospun Fibers-Elucidating Key Parameters and Developing Strategies for Drug Delivery. Int. J. Pharm. 2015, 478, 390-397.

(14) Tort, S.; Yıldız, A.; Tuğcu-Demiröz, F.; Akca, G.; Kuzukıran, Ö.; Acartürk, F. Development and Characterization of Rapid Dissolving Ornidazole Loaded PVP Electrospun Fibers. Pharm. Dev. Technol. 2019, 24, 864-873.

(15) Bukhary, H.; Williams, G. R.; Orlu, M. Electrospun Fixed Dose Formulations of Amlodipine Besylate and Valsartan. Int. J. Pharm. 2018, 549, 446-455.

(16) Illangakoon, U. E.; Gill, H.; Shearman, G. C.; Parhizkar, M.; Mahalingam, S.; Chatterton, N. P.; Williams, G. R. Fast Dissolving Paracetamol/Caffeine Nanofibers Prepared by Electrospinning. Int. J. Pharm. 2014, 477, 369-79.

(17) Nam, S.; Lee, S. Y.; Cho, H.-J. Phloretin-Loaded Fast Dissolving Nanofibers for the Locoregional Therapy of Oral Squamous Cell Carcinoma. J. Colloid Interface Sci. 2017, 508, 112120.

(18) Giram, P. S.; Shitole, A.; Nande, S. S.; Sharma, N.; Garnaik, B. Fast Dissolving Moxifloxacin Hydrochloride Antibiotic Drug from Electrospun Eudragit L-100 Nonwoven Nanofibrous Mats. Mater. Sci. Eng. C 2018, 92, 526-539.

(19) Mano, F.; Martins, M.; Sá-Nogueira, I.; Barreiros, S.; Borges, J. P.; Reis, R. L.; Duarte, A. R. C.; Paiva, A. Production of Electrospun Fast-Dissolving Drug Delivery Systems with Therapeutic Eutectic Systems Encapsulated in Gelatin. AAPS PharmSciTech 2017, 18, 2579-2585.

(20) Thakkar, S.; More, N.; Sharma, D.; Kapusetti, G.; Kalia, K.; Misra, M. Fast Dissolving Electrospun Polymeric Films of AntiDiabetic Drug Repaglinide: Formulation and Evaluation. Drug Dev. Ind. Pharm. 2019, 45, 1921-1930.

(21) Ponrasu, T.; Chen, B.-H.; Chou, T.-H.; Wu, J.-J.; Cheng, Y.-S. Fast Dissolving Electrospun Nanofibers Fabricated from Jelly Fig Polysaccharide/Pullulan for Drug Delivery Applications. Polymers 2021, 13, 241.

(22) Qin, Z.-y.; Jia, X.-W.; Liu, Q.; Kong, B.-h.; Wang, H. Fast Dissolving Oral Films for Drug Delivery Prepared from Chitosan/ Pullulan Electrospinning Nanofibers. Int. J. Biol. Macromol. 2019, 137, 224-231.

(23) Bilensoy, E. Cyclodextrins in Pharmaceutics, Cosmetics, and Biomedicine: Current and Future Industrial Applications; John Wiley \& Sons, 2011.

(24) Crini, G. History of Cyclodextrins. Chem. Rev. 2014, 114, 10940-10975.

(25) Carneiro, S.; Duarte, F. C.; Heimfarth, L.; Quintans, J. S.; Quintans-Júnior, L.; Júnior, V. V.; de Lima, Á. N.; da Veiga Júnior, V. F.; de Lima, Á. A. N. Cyclodextrin-Drug Inclusion Complexes: In Vivo and In Vitro Approaches. Int. J. Mol. Sci. 2019, 20, 642.

(26) Kalepu, S.; Nekkanti, V. Insoluble Drug Delivery Strategies: Review of Recent Advances and Business Prospects. Acta Pharm. Sin. B 2015, 5, 442-453.

(27) Aytac, Z.; Ipek, S.; Erol, I.; Durgun, E.; Uyar, T. Fast-Dissolving Electrospun Gelatin Nanofibers Encapsulating Ciprofloxacin/Cyclodextrin Inclusion Complex. Colloids Surf. B Biointerfaces 2019, 178, $129-136$.

(28) Samprasit, W.; Akkaramongkolporn, P.; Ngawhirunpat, T.; Rojanarata, T.; Kaomongkolgit, R.; Opanasopit, P. Fast Releasing 
Oral Electrospun PVP/CD Nanofiber Mats of Taste-Masked Meloxicam. Int. J. Pharm. 2015, 487, 213.

(29) Yildiz, Z. I.; Uyar, T. Fast-Dissolving Electrospun Nanofibrous Films of Paracetamol/Cyclodextrin-Inclusion Complexes. Appl. Surf. Sci. 2019, 492, 626-633.

(30) Celebioglu, A.; Uyar, T. Electrospun Formulation of Acyclovir/ Cyclodextrin Nanofibers for Fast-Dissolving Antiviral Drug Delivery. Mater. Sci. Eng. C 2021, 118, 111514.

(31) Yildiz, Z. I.; Celebioglu, A.; Uyar, T. Polymer-Free Electrospun Nanofibers from Sulfobutyl Ether7-Beta-Cyclodextrin (SBE7- $\beta$-CD) Inclusion Complex with Sulfisoxazole: Fast-Dissolving and Enhanced Water-Solubility of Sulfisoxazole. Int. J. Pharm. 2017, 531, 550-558. (32) Celebioglu, A.; Uyar, T. Metronidazole/Hydroxypropyl- $\beta$ Cyclodextrin Inclusion Complex Nanofibrous Webs as FastDissolving Oral Drug Delivery System. Int. J. Pharm. 2019, 572, 118828 .

(33) Celebioglu, A.; Uyar, T. Fast Dissolving Oral Drug Delivery System Based on Electrospun Nanofibrous Webs of Cyclodextrin/ Ibuprofen Inclusion Complex Nanofibers. Mol. Pharm. 2019, 16, 4387-4398.

(34) Celebioglu, A.; Uyar, T. Hydrocortisone/Cyclodextrin Complex Electrospun Nanofibers for a Fast-Dissolving Oral Drug Delivery System. RSC Med. Chem. 2020, 11, 245-258.

(35) Shi, J.-H.; Chen, K.; Xu, Y. Characterization of the Inclusion Interaction between Prednisolone and Di-O-Methyl- $\beta$-Cyclodextrin: Spectroscopic Methods and Molecular Modeling. J. Mol. Liq. 2014, 194, 172-178.

(36) Palanisamy, M.; Khanam, J.; Nagalingam, A.; Gani, N. Experimental Design to Predict Process Variables in the Preparation of Cellulose Based Sustained Release Microspheres System Loaded with Prednisolone-Cyclodextrin Complex. Korean J. Chem. Eng. 2011, 28, 1990-2001.

(37) Palanisamy, M.; Khanam, J. Cellulose-Based Matrix Microspheres of Prednisolone Inclusion Complex: Preparation and Characterization. AAPS PharmSciTech 2011, 12, 388-400.

(38) Palanisamy, M.; Khanam, J. Solid Dispersion of Prednisolone: Solid State Characterization and Improvement of Dissolution Profile. Drug Dev. Ind. Pharm. 2011, 37, 373-386.

(39) Couto, A. S.; Vieira, J.; Florindo, H. F.; Videira, M. A.; CabralMarques, H. M. Characterisation of DM- $\beta$-Cyclodextrin: Prednisolone Complexes and Their Formulation as Eye Drops. J. Inclusion Phenom. Macrocyclic Chem. 2014, 80, 155-164.

(40) Bílková, E.; Sedlák, M.; Dvorák, B.; Ventura, K.; Knotek, P.; Beneš, L. Prednisolone- $\alpha$-Cyclodextrin-Star PEG Polypseudorotaxanes with Controlled Drug Delivery Properties. Org. Biomol. Chem. 2010, 8, 5423-5430.

(41) Yano, H.; Hirayama, F.; Kamada, M.; Arima, H.; Uekama, K. Colon-Specific Delivery of Prednisolone-Appended $\alpha$-Cyclodextrin Conjugate: Alleviation of Systemic Side Effect after Oral Administration. J. Controlled Release 2002, 79, 103-112.

(42) Bíró, T.; Horvát, G.; Budai-Szűcs, M.; Csányi, E.; Urbán, E.; Facskó, A.; Szabó-Révész, P.; Csóka, I.; Aigner, Z. Development of Prednisolone-Containing Eye Drop Formulations by Cyclodextrin Complexation and Antimicrobial, Mucoadhesive Biopolymer. Drug Des., Dev. Ther. 2018, 12, 2529.

(43) Basu, B.; Aviya, K. R.; Bhattacharya, A. Development and Characterization of Mouth Dissolving Tablets of Prednisolone. J. Pharm. Invest. 2014, 44, 79-102.

(44) Larsen, K. L.; Aachmann, F. L.; Wimmer, R.; Stella, V. J.; Kjølner, U. M. Phase Solubility and Structure of the Inclusion Complexes of Prednisolone and $6 \alpha$-methyl Prednisolone with Various Cyclodextrins. J. Pharm. Sci. 2005, 94, 507-515.

(45) Tabuchi, R.; Anraku, M.; Iohara, D.; Ishiguro, T.; Ifuku, S.; Nagae, T.; Uekama, K.; Okazaki, S.; Takeshita, K.; Otagiri, M.; Hirayama, F. Surface-Deacetylated Chitin Nanofibers Reinforced with a Sulfobutyl Ether $\beta$-Cyclodextrin Gel Loaded with Prednisolone as Potential Therapy for Inflammatory Bowel Disease. Carbohydr. Polym. 2017, 174, 1087-1094.
(46) Tawfik, E. A.; Scarpa, M.; Abdelhakim, H. E.; Bukhary, H. A.; Craig, D. Q. M.; Barker, S. A.; Orlu, M. A Potential Alternative Orodispersible Formulation to Prednisolone Sodium Phosphate Orally Disintegrating Tablets. Pharmaceutics 2021, 13, 120.

(47) Higuchi, T.; Connors, K. A. Phase Solubility Diagram. Adv. Anal. Chem. Instrum. 1965, 4, 117-212.

(48) Bi, Y.; Sunada, H.; Yonezawa, Y.; Danjo, K.; Otsuka, A.; IIDA, K. Preparation and Evaluation of a Compressed Tablet Rapidly Disintegrating in the Oral Cavity. Chem. Pharm. Bull. 1996, 44, 21212127.

(49) Kresse, G.; Furthmüller, J. Efficient Iterative Schemes for Ab Initio Total-Energy Calculations Using a Plane-Wave Basis Set. Phys. Rev. B: Condens. Matter Mater. Phys. 1996, 54, 11169.

(50) Kohn, W.; Sham, L. J. Self-Consistent Equations Including Exchange and Correlation Effects. Phys. Rev. 1965, 140, A1133.

(51) Hohenberg, P.; Kohn, W. Inhomogeneous Electron Gas. Phys. Rev. 1964, 136, B864.

(52) Perdew, J. P.; Burke, K.; Ernzerhof, M. Generalized Gradient Approximation Made Simple [Phys. Rev. Lett. 77, 3865 (1996)]. Phys. Rev. Lett. 1997, 78, 1396.

(53) Grimme, S. Semiempirical GGA-type Density Functional Constructed with a Long-range Dispersion Correction. J. Comput. Chem. 2006, 27, 1787-1799.

(54) Blöchl, P. E. Projector Augmented-Wave Method. Phys. Rev. B: Condens. Matter Mater. Phys. 1994, 50, 17953.

(55) Mathew, K.; Sundararaman, R.; Letchworth-Weaver, K.; Arias, T. A.; Hennig, R. G. Implicit Solvation Model for Density-Functional Study of Nanocrystal Surfaces and Reaction Pathways. J. Chem. Phys. 2014, 140, 84106.

(56) Celebioglu, A.; Uyar, T. Electrospinning of Cyclodextrins: Hydroxypropyl-Alpha-Cyclodextrin Nanofibers. J. Mater. Sci. 2020, 55, 404-420.

(57) Xue, J.; Wu, T.; Dai, Y.; Xia, Y. Electrospinning and Electrospun Nanofibers: Methods, Materials, and Applications. Chem. Rev. 2019, 119, 5298-5415.

(58) Frey, M. W.; Li, L. Electrospinning and Porosity Measurements of Nylon-6/Poly (Ethylene Oxide) Blended Nonwovens. J. Eng. Fibers Fabr. 2007, 2, 155892500700200100.

(59) Narayanan, G.; Boy, R.; Gupta, B. S.; Tonelli, A. E. Analytical Techniques for Characterizing Cyclodextrins and Their Inclusion Complexes with Large and Small Molecular Weight Guest Molecules. Polym. Test. 2017, 62, 402-439.

(60) Yuan, C.; Liu, B.; Liu, H. Characterization of Hydroxypropyl- $\beta$ Cyclodextrins with Different Substitution Patterns via FTIR, GCMS, and TG-DTA. Carbohydr. Polym. 2015, 118, 36-40.

(61) Yang, Y.; Xie, B.; Liu, Q.; Kong, B.; Wang, H. Fabrication and Characterization of a Novel Polysaccharide Based Composite Nanofiber Films with Tunable Physical Properties. Carbohydr. Polym. 2020, 236, 116054.

(62) Shao, P.; Niu, B.; Chen, H.; Sun, P. Fabrication and Characterization of Tea Polyphenols Loaded Pullulan-CMC Electrospun Nanofiber for Fruit Preservation. Int. J. Biol. Macromol. 2018, $107,1908-1914$

(63) Ledeti, I.; Bengescu, C.; Cîrcioban, D.; Vlase, G.; Vlase, T.; Tomoroga, C.; Buda, V.; Ledeti, A.; Dragomirescu, A.; Murariu, M. Solid-State Stability and Kinetic Study of Three Glucocorticoid Hormones: Prednisolone, Prednisone and Cortisone. J. Therm. Anal. Calorim. 2020, 141, 1-13.

(64) Mura, P. Analytical Techniques for Characterization of Cyclodextrin Complexes in the Solid State: A Review. J. Pharm. Biomed. Anal. 2015, 113, 226-238.

(65) Celebioglu, A.; Uyar, T. Development of Ferulic Acid/ Cyclodextrin Inclusion Complex Nanofibers for Fast-Dissolving Drug Delivery System. Int. J. Pharm. 2020, 584, 119395.

(66) Barba, C.; Eguinoa, A.; Maté, J. I. Preparation and Characterization of $\beta$-Cyclodextrin Inclusion Complexes as a Tool of a Controlled Antimicrobial Release in Whey Protein Edible Films. LWT-Food Sci. Technol. 2015, 64, 1362-1369. 
(67) Woldum, H. S.; Larsen, K. L.; Madsen, F. Cyclodextrin Controlled Release of Poorly Water-Soluble Drugs from Hydrogels. Drug Deliv 2008, 15, 69-80.

(68) Zia, V.; Rajewski, R. A.; Stella, V. J. Effect of Cyclodextrin Charge on Complexation of Neutral and Charged Substrates: Comparison of (SBE) $7 \mathrm{M}-\beta-\mathrm{CD}$ to HP- $\beta$-CD. Pharm. Res. 2001, $18,667-673$.

(69) Loftsson, T.; Frikdriksdóttir, H.; Sigurkdardóttir, A. M.; Ueda, H. The Effect of Water-Soluble Polymers on Drug-Cyclodextrin Complexation. Int. J. Pharm. 1994, 110, 169-177.

(70) Celebioglu, A.; Uyar, T. Electrohydrodynamic Encapsulation of Eugenol-Cyclodextrin Complexes in Pullulan Nanofibers. Food Hydrocolloids 2021, 111, 106264.

(71) Peppas, N. A.; Narasimhan, B. Mathematical Models in Drug Delivery: How Modeling Has Shaped the Way We Design New Drug Delivery Systems. J. Controlled Release 2014, 190, 75-81.

(72) Li, X.; Kanjwal, M. A.; Lin, L.; Chronakis, I. S. Electrospun Polyvinyl-Alcohol Nanofibers as Oral Fast-Dissolving Delivery System of Caffeine and Riboflavin. Colloids Surf. B Biointerfaces 2013, 103, $182-188$. 